NBER WORKING PAPER SERIES

PRICE CUTTING AND BUSINESS STEALING IN IMPERFECT CARTELS

\author{
B. Douglas Bernheim \\ Erik Madsen \\ Working Paper 19993 \\ http://www.nber.org/papers/w19993 \\ NATIONAL BUREAU OF ECONOMIC RESEARCH \\ 1050 Massachusetts Avenue \\ Cambridge, MA 02138 \\ March 2014
}

We would like to thank Susan Athey, Kyle Bagwell, Lanier Benkard, Jeremy Bulow, Ben Golub, Leslie Marx, David McAdams, Andy Skrzypacz, Takuo Sugaya, Robert Wilson, and Alex Wolitsky for valuable discussions and feedback. We are especially indebted to Jonathan Levin for insightful guidance that helped to shape the project at critical stages. We are also grateful for comments by seminar participants at Stanford University, Stanford GSB, and the 12th Columbia/Duke/MIT/Northwestern IO theory conference. Both authors acknowledge financial support from the National Science Foundation. The views expressed herein are those of the authors and do not necessarily reflect the views of the National Bureau of Economic Research.

At least one co-author has disclosed a financial relationship of potential relevance for this research. Further information is available online at http://www.nber.org/papers/w19993.ack

NBER working papers are circulated for discussion and comment purposes. They have not been peerreviewed or been subject to the review by the NBER Board of Directors that accompanies official NBER publications.

(C) 2014 by B. Douglas Bernheim and Erik Madsen. All rights reserved. Short sections of text, not to exceed two paragraphs, may be quoted without explicit permission provided that full credit, including (C) notice, is given to the source. 
Price Cutting and Business Stealing in Imperfect Cartels

B. Douglas Bernheim and Erik Madsen

NBER Working Paper No. 19993

March 2014

JEL No. D43,L41

\begin{abstract}
Though economists have made substantial progress toward formulating theories of collusion in industrial cartels that account for a variety of fact patterns, important puzzles remain. Standard models of repeated interaction formalize the observation that cartels keep participants in line through the threat of punishment, but they fail to explain two important factual observations: first, apparently deliberate cheating actually occurs; second, it frequently goes unpunished even when it is detected. We propose a theory of "equilibrium price cutting and business stealing" in cartels to bridge this gap between theory and observation.
\end{abstract}

B. Douglas Bernheim

Department of Economics

Stanford University

Stanford, CA 94305-6072

and NBER

bernheim@stanford.edu

Erik Madsen

655 Knight Way, Knight Management Center

Graduate School of Business, Stanford University

Stanford, CA 94305-7298

ztrang@gmail.com 


\title{
Price cutting and business stealing in imperfect cartels *
}

\author{
B. Douglas Bernheim \\ Erik Madsen \\ Stanford University \\ Stanford GSB \\ and \\ NBER
}

March 2014

\begin{abstract}
Though economists have made substantial progress toward formulating theories of collusion in industrial cartels that account for a variety of fact patterns, important puzzles remain. Standard models of repeated interaction formalize the observation that cartels keep participants in line through the threat of punishment, but they fail to explain two important factual observations: first, apparently deliberate cheating actually occurs; second, it frequently goes unpunished even when it is detected. We propose a theory of "equilibrium price cutting and business stealing" in cartels to bridge this gap between theory and observation.
\end{abstract}

\section{Introduction}

An important objective of theoretical research in Industrial Organization is to achieve a conceptual understanding of the mechanisms through which actual price-fixing cartels arrive at collusive outcomes. Analyses of strategic models involving repeated interaction have yielded

*We would like to thank Susan Athey, Kyle Bagwell, Lanier Benkard, Jeremy Bulow, Ben Golub, Leslie Marx, David McAdams, Andy Skrzypacz, Takuo Sugaya, Robert Wilson, and Alex Wolitsky for valuable discussions and feedback. We are especially indebted to Jonathan Levin for insightful guidance that helped to shape the project at critical stages. We are also grateful for comments by seminar participants at Stanford University, Stanford GSB, and the 12th Columbia/Duke/MIT/Northwestern IO theory conference. Both authors acknowledge financial support from the National Science Foundation. 
important insights but also leave significant gaps. ${ }^{1}$ A serious shortcoming of the simplest such theories is that neither deliberate cheating nor punishment occurs in equilibrium, even though both are observed in practice. ${ }^{2}$ Extensions involving imperfect monitoring (beginning with Green and Porter (1984)) explain why punishments (such as price wars) are observed, but do not account for deliberate cheating: in equilibrium, punishments are triggered only by events beyond the control of the cartel members, and not by their intentional choices. ${ }^{3}$ Moreover, according to those theories, if cheating did occur and were detected, it would definitely trigger punishment.

Yet it appears that observed price cutting and business stealing often goes unpunished, with cartel members instead reminding each other that "our competitors are our friends and our customers are our enemies" 4 and urging one another to recall their common interests and let cooler heads prevail. Examples of such forbearance litter the record of the discordant cartels surveyed by Marshall et al. (2013). ${ }^{5}$ For instance, the global lysine cartel, which

\footnotetext{
${ }^{1}$ Leading papers developing theories of collusion in price-fixing cartels in a variety of environments include Green and Porter (1984), Rotemberg and Saloner (1986), Abreu et al. (1986), Abreu (1988), Bernheim and Whinston (1990), Athey and Bagwell (2001), Athey et al. (2004), Athey and Bagwell (2008), and Harrington and Skrzypacz (2011).

${ }^{2}$ Instances of cheating on cartel agreements, in particular price cuts below an agreed target and stealing of customers allocated to competitors, have been frequently identified in the context of antitrust cases. Marshall et al. (2013) provide an excellent survey derived from European Commission decisions on major industrial cartels from 2000 to 2005. Of 22 rulings over that period, they classify 9 as "discordant," a designation indicating "evidence of frequent bargaining problems and deviations by cartel members, occuring throughout the cartel period," based on their reading of the EC decisions. Only 6 are classified as fully concordant, meaning that the cartel functioned smoothly through the collusive period. The proportion of discordant cartels in the population is likely understated, in light of the inherent selection bias in their sample towards cartels effective enough to draw antitrust scrutiny. Levenstein and Suslow (2006) compile a comprehensive survey of empirical studies of the coordination difficulties faced by major industrial cartels, and emphasize the potential selection issues. Harrington (2006) provides further discussion of the evidence from EC cartel decisions of the early 2000s.

Examples of punishments, including industry-wide price wars as well as more targeted retaliation, have been widely discussed in the literature; see, e.g., Porter (1983), Green and Porter (1984), Genesove and Mullin (1998, 2001), Harrington (2006), and Marshall et al. (2013).

3 To be clear, the theory of imperfect monitoring can in principle account for unintended cheating, such as apparent defections from collusive agreements attributable to "rogue employees" who are not involved in the conspiracy. In particular, one could construct a model with imperfectly controlled sales personnel whom, in equilibrium, each firm would instruct to quote some collusive prices (which means deliberate cheating would not occur). However, analogously to Green and Porter (1984), "rogue" salespeople would periodically grant price concessions (e.g., with the object of enhancing their own compensation given their false understanding of their employer's objectives). Because other firms would be unable to distinguish between actual and rogue defections, all defections would have to occasionally trigger punishments.

${ }^{4}$ This precise statement was in fact made by Archer Daniels Midland president James Randall to executives of a Japanese lysine producer in an April 30, 1993 meeting. http://www.nytimes.com/1998/08/04/ business/videotapes-take-star-role-at-archer-daniels-trial.html

${ }^{5}$ In what follows, we draw extensively on the text of antitrust decisions by the European Commission, which are published in the Official Journal of the European Union and available online at
} 
operated at least from 1992 through 1995, discussed a persistent and substantial gap between target and actual prices in its European markets at cartel meetings throughout 1993 and 1994. This gap was variously attributed to arbitrage by commodity traders and fluctuating exchange rates, but was eventually blamed on undercutting by particular cartel members. ${ }^{6}$ These difficulties culminated in a "reset" by the cartel, during which sales were briefly suspended in order to drive up the price to the collusive target. ${ }^{7}$ However, there is no indication in the record that the deviators were punished.

A cartel producing nucleotides for use as food flavor enhancers, which operated in Europe from 1988 to 1999, encountered similar difficulties. The cartel attempted to allocate sales to several large nucleotide purchasers among its members. During meetings spanning 1991 to 1996, cartel members complained about low prices and requests by their customers to match reduced quotes provided by other cartel members. There is no evidence that punishments for these deviations were contemplated or implemented; rather, in each instance the cartel simply set a new price and urged its members to abide by the latest figure. ${ }^{8}$

Likewise, a cartel of citric acid producers in western Europe operating from 1991 to 1995 endured persistent suspicions of undercutting by one of its members, Jungbunzlauer, for the latter half of the cartel period. The cartel convened special recurring sessions alongside the main cartel meetings to monitor and discuss Jungbunzlauer's behavior, but apparently never modified the collusive arrangement in response. The cartel's abrupt collapse in 1995 could perhaps be interpreted as a coordinated but belated punishment for Jungbunzlauer's actions, but more likely reflected a general collapse of coordination. ${ }^{9}$

http://ec.europa.eu/competition/cartels/cases/cases.html

${ }^{6}$ The form of the undercutting was often deliberately contrived to skirt the letter of cartel agreements. For example, Sewon Europe, which accused Eurolysine of particularly flagrant deviations, complained at one point that "actual market prices had always dropped after the announcement of price increases, because Eurolysine announced a price increase after securing orders from big customers at the old price " and that "agreed prices had been rendered meaningless due to the fact that Eurolysine was selling quantities in advance at a price lower than the agreed price." (EC Decision on Amino Acids (COMP/36.545/F3), paragraphs 138 and 148.)

${ }^{7}$ EC Decision on Amino Acids, paragraph 151. It is unclear how successful this intervention proved. No further complaints were lodged publicly against Eurolysine, but the cartel continued to struggle with declining European prices attributed to arbitrage trading and resale by distributors. (Paragraphs 158, 161-2, and 164-5.) Further, a final meeting prior to the discovery of the cartel contemplated an explicit division of European customers between producers. This suggests that the European branch of the cartel may have experienced continued dysfunction following the "reset."

${ }^{8}$ Complaints of undercutting and business stealing were lodged with remarkable regularity, bordering on repetitiveness. (EC Decision on Food Flavour Enhancers (COMP/C.37.671), paragraphs 94, 104, 109, 111-2, $114,116,118,121,129$, and 148.) In only one case was the possibility of an enforcement mechanism alluded to. (Paragraph 112.) It was never followed up in the record. Puzzlingly, in a meeting described in paragraph 126, cartel members congratulated themselves on the success of their cooperation - only a few months after the complaints of paragraph 121 and prior to the accusations of paragraph 129 .

${ }^{9}$ The collapse of the cartel, occurring in the early months of 1995, was apparently quite chaotic: "[T]hree 
As a final example, the Sugar Institute, which operated throughout the 1920s, experienced frequent episodes of cheating by members. A typical pattern was for cartel members to secretly skirt the cartel's price maintenance rules via indirect price cuts or kickback schemes, and then to apologize and halt a practice when it was uncovered. The cartel would update its rules to explicitly bar that practice, and members would proceed to devise new schemes to skirt the updated rules. Such tactics appear to have been tolerated without retaliation by cartel members, provided misconduct did not continue after it was uncovered, and this habit of forbearance does not seem to have substantially vitiated the efficacy of the cartel. (Genesove and Mullin (2001).)

These unresolved empirical puzzles have important practical implications, in that attorneys for companies accused of collusion often point to evidence of price cuts and business stealing, and to a purported lack of retaliation, as "proof" that a cartel is ineffective. This strategy was employed, for instance, by defense attorneys during the criminal prosecution of several top ADM executives following discovery of the lysine cartel. ${ }^{10}$ It was also a common claim by defendents in the various EC decisions surveyed in Marshall et al. (2013). ${ }^{11}$

meetings on 6 January $1995 \ldots$ did not fundamentally change any previous pattern of behaviour. The other undertakings attacked Jungbunzlauer for its 'almost total lack of adherence to the agreed prices which Jungbunzlauer had reduced'... [W]hilst the atmosphere was 'much less friendly' and the group was starting to fall apart, monthly sales data continued to be regularly exchanged and all parties were still very much in contact with each other... It was not until the last, unplanned, meeting on 22 May 1995... that it became clear that 'the cartel was in total disarray and was not working. [Jungbunzlauer] was told that unless JBL was seen to do something to repair the damage that they had done the agreement was at an end'." (EC Decision on Citric Acid (COMP/E-1/36 604), paragraphs 125-6.)

It is unclear what actions, if any, Jungbunzlauer was prepared to take, as the cartel was uncovered less than a month later.

${ }^{10}$ According to news coverage in the September 10, 1998 edition of the Chicago Tribune: "Top executives of Archer Daniels Midland Co. 'busted up a longstanding Asian cartel,' introducing 'fierce competition' into the market for a livestock-feed additive, a defense attorney said... [ADM] was 'stealing customers' and 'undercutting competitors' at the time prosecutors say it was carving up the lysine business... [C]ompetitors lied to each other routinely, he said. 'This is not Business Ethics 101. This is how you deal with the real world. You have to mislead the competition'." http://articles.chicagotribune.com/1998-09-10/ business/9809100377_1_lysine-michael-andreas-mark-whitacre

11 Citric acid: "ADM and Jungbunzlauer contend that from 1993 onwards, price increases were no longer implemented... [A report commissioned by ADM] also submits that the great majority of ADM's sales... were at prices below the floor price. This would lend support to the conclusion that pricing during the relevant period resulted more from a situation of oligopolistic competition than from coordination." (EC Decision on Citric Acid, paragraphs 221-3.)

Food flavor enhancers: "Ajinomoto submits that it not only proved very difficult to reach agreements on target prices, but that even where agreements were reached, these agreements were never fully complied with: deviation from the arrangements was frequent and not punished and no effective monitoring system was established. Consequently, according to Ajinomoto, the infringement was not fully implemented." (EC Decision on Food Flavour Enhancers, paragraph 231.)

Industrial tubes: "KME and Wieland Werke [claim] that the cartel was not fully implemented. Because non-compliance was not punished, deviation could not be avoided. They cite a number of incidents of 
Though intuitively plausible, the possibility that an imperfect but nevertheless effective real-world cartel might exhibit some degree of deliberate price cutting and business stealing, and that such behavior might sometimes go unpunished despite detection, has as yet found no rigorous theoretical articulation. In this paper, we attempt to bridge this important gap between theory and observation by constructing a theory of equilibrium price cuts and business stealing in imperfectly effective cartels. We formulate a model in which firms have natural advantages with respect to serving particular market segments and must incur fixed costs (e.g., establish a local office, make relationship investments, and/or incur bid preparation costs) before attempting to do business with any specific customer (or group of customers). For intermediate discount factors, some collusion is feasible but perfect collusion is not. Our agenda is to study the properties of imperfectly collusive equilibria in those settings.

Beginning with the case of two firms, our first main result shows that, under reasonably general conditions, imperfectly collusive equilibria necessarily involve price cuts and business stealing, in the sense that firms price below an aspirational cartel price with positive probability and no firm wins any customer with certainty (even though the model is deterministic). Our second main result demonstrates that the best collusive equilibria within an important class have several key properties. First, the cartel in effect attempts to divide the market according to the firms' relative advantages. Second, while the cartel may establish an aspirational price (in our model, the monopoly price), it recognizes that perfect collusion is unsustainable, and consequently also explicitly or implicitly establishes a price floor, at which each firm can be assured of locking up its "home market." Third, each firm often charges the aspirational price in its home market, but also sometimes cuts its price in an attempt to defend market share against anticipated "raids" by competitors. Fourth, firms sometimes

deviation and customer fluctuations... to demonstrate that the infringement was not fully implemented." (EC Decision on Industrial Tubes (COMP/E-1/38.240), paragraph 356.)

Lysine: "ADM, Ajinomoto, Sewon and Cheil suggest that they did not, in practice, implement the offending agreements... ADM states that... its actual European transaction prices charged around the time of each price agreement referred to in the present Decision were lower than those agreed upon. ADM contends that the other producers were well aware that it was not implementing any agreed terms... Sewon claims that it consistently undercut the agreed target prices... Cheil states that its prices were almost always the lowest in the market, in some cases up to $25 \%$ lower than the prices charged by the other companies... Ajinomoto suggests that it is apparent from the data... that the cartel members did not keep to agreed prices... ADM states that it substantially exceeded its allocations each year." (EC Decision on Amino Acids, paragraphs 366-374.)

Zinc phosphate: "Failure to adhere to the agreed prices is also put forward by Britannia, Heubach, SNCZ, Trident and Waardals. All of them contend that there was no impact on the market, as the fixed prices were not respected and competition continued to prevail." (EC Decision on Zinch Phosphate (COMP/E1/37.027), paragraph 291.) 
attempt to raid each others' markets, in all such cases setting prices above the floor, so as to avoid stealing business if the home firm has made the "safe" choice. If, however, the home firm has also set a price above the floor, the rival may successfully steal business. Fifth, whenever such price cuts or business stealing occur, they go unpunished. However, the cartel would punish business stealing by "away" firms at or below the floor. Thus, we demonstrate that deliberate and unpunished price cuts and business stealing (which would appear to observers as "cheating") can be critical to the healthy functioning of a cartel. ${ }^{12}$

Our theory therefore has implications for the relationship between conduct and patience that contrast markedly with conventional accounts. In an ideal world, cartels would like to divide the market among their members at the monopoly price. However, sustaining this division requires a certain degree of patience among firms, as in a standard Folk Theorem. In classical cartel models, insufficiently patient firms adapt by lowering the collusive price, without any further modification to the collusive structure; see Figure 1, Panel A. ${ }^{13}$

Our analysis points to an alternative mode of conduct: rather than coordinate on a lower price, the cartel (optimally) attempts to achieve the aspirational monopoly price, but succeeds only imperfectly. The temptation to undercut the monopoly price is of course too strong to sustain monopoly profits, and (crucially) all firms understand this. So cartel members protect themselves by occasionally cutting prices in their own market, to head off raids by their competitors. These raids still sometimes occur and competitors may successfully steal business, but an explicit or implicit price floor below which raids are unacceptable (and punished harshly) limits the resulting discord. The atom at the monopoly price reflects each firm's partial adherence to the aspirational agreement, while the floor price demarcates the point at which firms are comfortable they can secure their market against raids by competitors; see Figure 1, Panel B. ${ }^{14}$

The theory thus predicts that, instead of (or possibly in addition to) lowering the aspirational price (which in our particular model is always the monopoly price), impatience may result in greater apparent discord and price-cutting relative to that price, without entirely undermining the efficacy of the cartel. Crucially, the price-cutting is defensive, to head off anticipated raids, which materialize just often enough to justify the price cuts. This theory also has a potentially testable implication: unpunished business stealing occurs at

\footnotetext{
${ }^{12}$ For a complementary perspective on these issues, see the recent work of Rahman (2014).

${ }^{13}$ Our model involves price competition among firms producing homogeneous products. For standard Bertrand competition, the curve in Panel A would exhibit a discontinuous jump from the competitive price level to the monopoly price level at a threshold discount factor.

${ }^{14}$ For the particular Bertrand-style model we examine, the aspirational price is always the monopoly price, as shown in the figure. However, with other models of competition, both the aspirational price and the price floor might be increasing in $\delta$.
} 


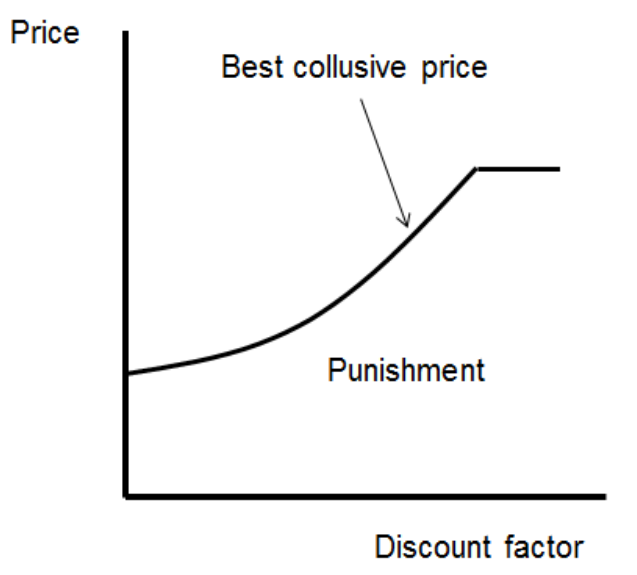

Panel A: Conventional view of best collusive arrangement

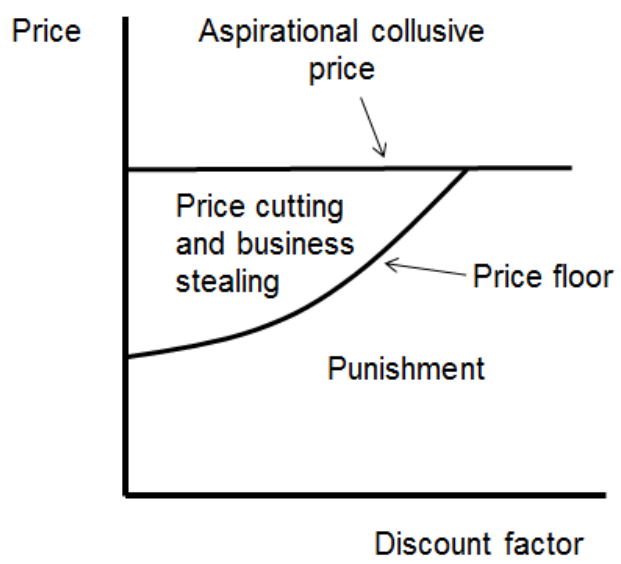

Panel B: Optimal collusion

Figure 1: The nature of collusion

prices above the cartel's floor, whereas all business stealing at prices below that floor triggers punishment. ${ }^{15}$ In practice, this implication may prove difficult to test because a cartel's price floor may not be known with precision (indeed, in practice, price agreements can appear somewhat fuzzy). For this purpose, one cannot use the average price as a proxy for the floor, because the theory implies that some business stealing will occur at below-average prices. A more robust testable implication of the theory is that, the higher the price at which business is stolen, the lower the likelihood that apparent "cheating" will trigger punishement. Testing this implication falls outside the scope of our current theoretical inquiry.

The rest of this paper is organized as follows. We present the basic model of industrial competition in section 2 . Section 3 characterizes the properties of non-collusive equilibria (i.e., equilibria in one-shot play). Section 4 presents results for the case of two firms, and section 5 explains how those results extend to settings with more than two firms. Some brief concluding remarks appear in section 6. All proofs are collected in the Appendix.

\section{The model}

A set of firms compete for the business of a collection of customers in an infinite sequence of discrete periods $(t=1,2, \ldots)$. For the time being, we assume that there are two firms

\footnotetext{
${ }^{15}$ Technically, in our model, business stealing below the price floor occurs with probability zero. However, in a more general model it could occur for unrelated reasons, such as imperfect control over "rogue" salespeople who have no knowledge of the cartel; see footnote 3.
} 
$(i=1,2)$ and two markets. The firms are risk-neutral profit maximizers and share a common discount factor $\delta \in(0,1)$. They are also differentiated, with each holding a (symmetric) comparative advantage in one of the two markets. For concreteness and simplicity, we model these advantages as pertaining to costs: the marginal cost of production is $c_{H}$ in a firm's home market and $c_{A}$ in its away market, where $\Delta c \equiv c_{A}-c_{H}>0$. In each period, each firm decides whether to attempt serving each market. Doing so causes the firm to incur a recurring market-specific fixed cost, $c$. In practice, this cost may have a variety of different components, including expenses associated with running a local office, tailoring products to local needs (e.g., to achieve "design wins"), and establishing and maintaining relationships with clients.

Each consumer views the products of the two firms as perfect substitutes, and has unit demand for all prices up to some privately known reservation value $v \sim G(\cdot)$, a CDF. (Equivalently, one can think of each market as containing a continuum of consumers with unit measure, with deterministic but privately known reservation values distributed according to G.) Consumers purchase the good from the firm offering the lowest price provided it does not exceed their reservation value $v$, with ties broken randomly.

Aggregate demand at price $p$ is given by $D(p) \equiv 1-\lim _{\hat{p} \uparrow p} G(\hat{p}) \cdot{ }^{16}$ We use $\underline{p}_{i}(i=H, A)$ to denote the single-firm break-even price (accounting for both $c_{i}$ and $c$ ), and $p_{i}^{*}$ to denote the monopoly price. To avoid uninteresting technical complications, we assume that these prices are well-defined and unique, and that single-firm profits would increase monotonically for prices between $c_{i}$ and $p_{i}^{*} .{ }^{17}$ These assumptions can be derived from more primitive restrictions on $G$, but neither the restrictions nor their derivation are enlightening in this context. We also assume that $\underline{p}_{A}<p_{H}^{*}$, i.e. that $\Delta c$ isn't too large, to ensure that the lowcost firm cannot simply blockade entry at the optimal single-firm price. (Precise technical restrictions on the demand function are given in the Appendix.)

For each market in each period, each firm's strategy is a pair $(\pi, F)$, where $\pi$ represents the probability of quoting a price and $F$ is a CDF governing the distribution of the price, conditional upon a quotation. Both decisions (whether and what to quote) are made at the same time, without knowledge of the other firm's choice.

\footnotetext{
${ }^{16}$ Note that we allow for the possibility that $G$ is discontinuous, to accommodate a leading special case in which firms know the customer's reservation value. We assume that consumers resolve indifference in favor of a purchase to assure existence of optimal pricing strategies.

${ }^{17}$ Because $D(p)$ is decreasing, a discontinuity on $\left[c_{i}, p_{i}^{*}\right)$ would violate monotonicity of $D(p)\left(p-c_{i}\right)$. Thus monotonicity implies that $D(p)$ is continuous on $\left[c_{i}, p_{i}^{*}\right)$. Note that monotonicity is still consistent with a (right-) discontinuity at $p_{i}^{*}$, so we do not rule out the case where firms know the customer's reservation value.
} 


\section{The non-collusive outcome}

Before studying collusion, we first characterize non-collusive outcomes by studying equilibria in a one-shot version of the game. The following theorem provides this characterization:

Theorem 1. There exists a unique Nash equilibrium of the stage game. In this equilibrium:

1. The home firm always quotes a price, while the away firm quotes a price with probability strictly between 0 and 1.

2. The home firm makes profits $\Pi_{H}=D\left(\underline{p}_{A}\right) \Delta c>0$, while the away firm makes zero profits.

3. Firms quote prices only in $\left[\underline{p}_{A}, p_{H}^{*}\right]$. Each firm's price distribution has full support on $\left[\underline{p}_{A}, p_{H}^{*}\right]$, and is atomless except at $p_{H}^{*}$, which the home firm chooses with strictly positive probability.

Several features of this equilibrium merit emphasis. First, the consumer always ends up paying strictly more than $\underline{p}_{A}$. This is significant because $\underline{p}_{A}$ is the lowest price that a high-cost firm would be willing to charge, and hence it is tempting to interpret $\underline{p}_{A}$ as the fully competitive price. Indeed, the expected profits earned by each firm are the same as if both set $\underline{p}_{A}$ and the consumer purchased from the home firm. However, the dissipative payment of fixed costs by both firms drives a wedge between the price paid by the consumer and industry profits even in a fully competitive outcome. Second, because the distribution of prices for both firms has full support on $\left[\underline{p}_{A}, p_{H}^{*}\right]$, the ex post outcome can appear arbitrarily collusive. Third, "business stealing" (defined here as the away firm winning sales) occurs with strictly positive probability.

\section{Optimal collusion}

Industry profits are maximized when each market is monopolized by the low-cost firm at price $p_{H}^{*}$. This perfectly collusive outcome serves as a natural benchmark for gauging the effectiveness of a collusive arrangement. ${ }^{18}$ We will refer to any equilibrium yielding profits strictly above the stage-game Nash level but below perfectly collusive level as an imperfectly collusive arrangement.

\footnotetext{
${ }^{18}$ To be sure, there exist other points along the firms' Pareto frontier. But such points are technologically inefficient and not robust to the introduction of side transfers.
} 
When firms are sufficiently patient, a folk theorem obtains in the sense that perfect collusion is sustainable as a subgame perfect Nash equilibrium. More precisely, there exists a critical discount factor $\delta^{M}<1$ above which perfect collusion is sustainable and below which it is not. We study collusion for discount factors below $\delta^{M}$.

We first establish that imperfect collusion is sustainable for a range of discount factors below $\delta^{M}{ }^{19}$ The main result of this section goes on to characterize optimal collusion within a natural class of equilibria. In the optimal equilibrium, firms set a floor price $p^{*}$ and divide the market according to cost advantage in each period, with firm $i$ capturing all the business in market $i$ whenever it charges $p^{*}$. Any undercutting of $p^{*}$ triggers a punishment phase yielding discounted continuation profits $\underline{\Pi}$. Even so, each firm sometimes raids its competitor's home market, quoting a price above $p^{*}$, and occasionally wins those customers because the home firm sometimes charges an even higher price. Successful raids into a competitor's home market goes unpunished when they takes this form. Our model thus predicts equilibrium business stealing.

\subsection{Stationary equilibria}

Characterizing the Pareto frontier of a repeated game for fixed discount factors is a difficult task. Several notable papers illustrate the inherent complexities. Abreu et al. (1990) construct a set-valued mapping, the largest fixed point of which is the set of SPNE payoffs, but they identify few general properties of the set. Mailath et al. (2002) characterize playeroptimal pure-strategy equilibria of the repeated prisoner's dilemma. They show that these equilibria are often non-stationary and cyclic, with arbitrarily long periodicity. Abreu and Sannikov (2014) examine extremal pure-strategy equilibria of two-player finite-action games. They show that the number of extremal equilibria is finite and bounded by the size of the action set, and that extremal payoffs are characterized by a system of nonlinear equations. We are aware of no work that attempts to derive similar characterizations for mixed-strategy equilibria in games with continuous action spaces.

To retain tractability and provide sharp characterizations of optimal collusion, we restrict attention to SPNEs exhibiting a natural stationary structure.

Definition 1. Fix an SPNE $\sigma$. We call $\sigma$ a stationary equilibrium if there exists a stagegame strategy profile $\tau$ and a set of game histories $\widetilde{\mathcal{H}}^{\infty} \subset \mathcal{H}^{\infty}$, the equilibrium path, such

\footnotetext{
${ }^{19}$ This result is not entirely obvious a priori. For instance, in symmetric Bertrand competition with no fixed costs, the equilibrium set has a "bang-bang" structure with perfect collusion sustainable for $\delta \geq 1 / 2$ and no collusion sustainable otherwise.
} 
that: 1) $\widetilde{\mathcal{H}}^{\infty}$ occurs with probability 1 under $\sigma$; and 2) $\sigma\left(h^{t}\right)=\tau$ after all partial histories $h^{t}$ lying on the equilibrium path. ${ }^{20}$

This definition singles out equilibria in which behavior looks "the same" in all periods so long as no deviations have taken place. It imposes no restrictions on equilibrium structure off-path (beyond subgame perfection), thereby allowing for optimal penal codes, which are generally non-stationary. In practice the equilibrium path of a stationary equilibrium is easy to describe, as it is generated by a set of "acceptable" action profiles that lead to a repetition of the same on-path stage-game strategy profile, $\tau$, at each stage. The support of $\tau$ is then necessarily a subset of the allowable action set, though not all acceptable actions need be played in equilibrium.

We restrict attention to stationary equilibria in part for reasons of tractability. We also regard them as potentially more appealing than many non-stationary alternatives due to their comparative simplicity. While we cannot rule out the possibility that non-stationary equilibria would improve upon an optimal stationary equilibrium, the advantages of nonstationarity - if any - are not obvious in this context. Furthermore, as we will show, optimal stationary equilibria have a surprisingly rich structure that matches important features of many real-world cartels.

\subsection{Optimal collusion in stationary equilibria}

In this section, we characterize maximum sustainable profits for stationary equilibria, and show that this optimum is achieved by equilibria that generate behavior interpretable as unpunished business stealing.

We first introduce a bit of useful notation. Let $\Pi^{C} \equiv D\left(\underline{p}_{A}\right)\left(\underline{p}_{A}-c_{A}\right)-c=\Delta c D\left(\underline{p}_{A}\right)$ be the "competitive" profits of the home firm in the unique Nash equilibrium of the stage game. Similarly, let $\Pi^{M} \equiv D\left(p_{H}^{*}\right)\left(p_{H}^{*}-c_{H}\right)-c$ be the stage profits of a monopolist in its home market. Plainly, the best stationary equilibrium must generate normalized discounted

\footnotetext{
${ }^{20}$ For a pure-strategy equilibrium, the equilibrium path is a singleton set consisting of the unique history picked out by $\sigma$. With mixed strategies and a continuum action space, many "on-path" partial histories might occur with probability zero, so we must attend to some technical details.

Interpreted as a behavioral strategy profile, $\sigma$ induces, for each $t$, a probability measure $\mu_{t}$ on the set of partial histories $\mathcal{H}^{t}$. By the Kolmogorov extension theorem, we can uniquely extend the collection $\left\{\mu_{t}\right\}_{t=1}^{\infty}$ to a measure $\mu$ on the set of complete histories $\mathcal{H}^{\infty}$. There then exists an equivalence class of measurable subsets of $\mathcal{H}^{\infty}$ with measure 1 under $\mu$.

A stationary equilibrium singles out some member $\widetilde{\mathcal{H}}^{\infty}$ of this class as the "equilibrium path." A partial history $h^{t} \in \mathcal{H}^{t}$ lies on the equilibrium path if there exists some $h^{\infty} \in \widetilde{\mathcal{H}}^{\infty}$ such that $\zeta_{t}\left(h^{\infty}\right)=h_{t}$, where $\zeta_{t}$ is the operator that projects a history onto its first $t$ dimensions.
} 
("lifetime") profits in the interval $\left[\Pi^{C}, \Pi^{M}\right] \cdot{ }^{21}$ At the opposite extreme, let $\underline{\Pi}(\delta)$ be the infimum of a firm's SPNE-supportable lifetime profits when the discount factor is $\delta$.

For $\Pi \in\left[\Pi^{C}, \Pi^{M}\right]$, we define $p^{*}(\Pi)$ as the price a monopolist would charge in its home market to achieve profits $\Pi$; formally it is the solution in $\left[\underline{p}_{A}, p_{H}^{*}\right]$ to $\Pi=D(p)\left(p-c_{H}\right)-c$. Given our assumptions on $D(\cdot), p^{*}(\cdot)$ exists and is single-valued, continuous, and strictly increasing.

Finally, let $\delta^{M}$ be the lowest (infimum) discount factor at which perfect collusion is sustainable. We show later that $\delta^{M}<1$ and that perfect collusion is always sustainable for $\delta \geq \delta^{M}$. More importantly, for a range of discount factors below $\delta^{M}$, we establish the existence of optimal stationary equilibria with the following structure:

1. In the cooperative phase, the home firm definitely enters the market, and the away firm enters with strictly positive probability. Both set prices between some $p^{*}$ and the home firm's monopoly price, $p_{H}^{*}$. The home firm quotes both $p^{*}$ and $p_{H}^{*}$ with strictly positive probability, while the away firm quotes prices strictly between these bounds. As a result, consumers sometimes make their purchases from the home firm, and sometimes from the away firm. Regardless of which firm prevails, the cooperative phase continues as long as no firm undercuts $p^{*}$. Only the away firm has an incentive to price below $p^{*}$ (because the home firm can win with certainty by quoting $p^{*}$ ); any such price quote triggers the punishment phase.

2. In the punishment phase, the firms engage in a price war yielding negative stage profits to both. If firms participate in the price war for a single period, the equilibrium reverts to the cooperative phase; otherwise the punishment phase starts over.

Plainly, the degree of collusion sustainable in the cooperative phase depends on the harshness of the price war that would follow a deviation. But at the same time, the harshness of the most severe sustainable price war depends on the future reward offered as recompense for participating. Therefore, as is typical in the analysis of repeated games, sustainable cooperation and punishment are determined simultaneously.

The following theorem characterizes the highest cooperative payoff taking as given the harshest punishment payoff $\underline{\Pi}(\delta)$, the value of which is not yet known. Because we restrict attention to stationary equilibria, no further information is needed concerning payoffs: all

\footnotetext{
${ }^{21} \mathrm{As}$ is standard in the literature, we normalize the NPV of a firm's income stream by $1-\delta$ to obtain lifetime profits, which are then interpretable as a weighted average per-period profitability, with weight $\delta^{t}(1-\delta)$ on the $t$ th period. For a stationary equilibrium path, lifetime profits are equal to the stage profits earned in each period.
} 
on-path continuations must deliver the cooperative payoff, and (without loss of generality) we can configure the equilibrium so that all deviations trigger the harshest possible punishment.

Theorem 2. For each $\delta \leq \delta^{M}$, the unique Pareto-optimal stationary equilibrium profit vector $\left(\Pi^{*}, \Pi^{*}\right)$ satisfies

$$
\Pi^{*}=(1-\delta)\left(2 \Pi^{*}-\Delta c D\left(p^{*}\left(\Pi^{*}\right)\right)\right)+\delta \underline{\Pi}(\delta) .
$$

Further, $\Pi^{*}>\Pi^{C}$ iff $\underline{\Pi}(\delta)<\Pi^{C}$, and $\Pi^{*}$ is strictly increasing in $\delta$ whenever $\underline{\Pi}(\cdot)$ is nonincreasing in $\delta$.

To understand this result intuitively, imagine for the moment that the best collusive arrangement divides the market along cost lines, and prescribes that each home firm satisfy all demand at a price $p^{*}\left(\Pi^{*}\right)<p_{H}^{*}$. (We will eventually exhibit optimal equilibria that have a similar structure, except that the home firm sometimes "cheats upward" from $p^{*}\left(\Pi^{*}\right)$, creating opportunities for unpunished business stealing, without changing expected profits.) Abiding by this agreement yields lifetime profits of $\Pi^{*}$ for each firm. A firm's most profitable deviation involves charging $p^{*}\left(\Pi^{*}\right)$ in its home market while slightly undercutting that price in its away market. The firm then earns (approximately) $\Pi^{*}-\Delta c D\left(p^{*}\left(\Pi^{*}\right)\right.$ ) for a single period before suffering the harshest punishment; as a result, its lifetime (normalized) payoff is $(1-\delta)\left(\Pi^{*}-\Delta c D\left(p^{*}\left(\Pi^{*}\right)\right)\right)+\delta \underline{\Pi}(\delta)$. Incentive compatibility requires that the latter expression is no greater than $\Pi^{*}$, and maximizing $\Pi^{*}$ subject to that constraint requires equality, as the theorem asserts.

Note that the Pareto frontier is degenerate, and both firms agree on the optimal collusive scheme. According to the theorem, there are no asymmetric optimal stationary equilibria.

The preceding characterization holds irrespective of the available punishments. Our next theorem characterizes the harshest sustainable punishment for settings in which firms are not too impatient.

Theorem 3. Suppose $\delta \geq \underline{\delta} \equiv \frac{1}{2+\Delta c D\left(p_{H}^{*}\right) / c}$. Then there exists an SPNE yielding lifetime profits of zero to both firms. Hence $\underline{\Pi}(\delta)=0$.

The punishment equilibrium supporting zero profits involves a short-term price war followed by optimal collusion afterward. In the first period, firms drive prices below the breakeven level. Both firms enter each market, the home firm sets some $p^{P W} \leq \underline{p}_{H}$, and the away firm mixes over a distribution with support on $\left(p^{P W}, \underline{p}_{H}\right]$. Thus the home firm serves the market at an unprofitable price, while the away firm loses money by incurring fixed costs. As long as both firms participate in the price war for one period, they transition to a phase with lifetime continuation profits of $\Pi^{*}$, which we characterized in Theorem 
2. Otherwise the punishment restarts. The price $p^{P W}$ is chosen so that lifetime profits $(1-\delta)\left(D\left(p^{P W}\right)\left(p^{P W}-c_{H}\right)-2 c\right)+\delta \Pi^{*}$ equal zero. The restriction on $\delta$ in the theorem ensures that $p^{P W} \leq \underline{p}_{H}$ and thus that a firm's best deviation yields zero single-period profits (which it can achieve by exiting both markets).

Our next result synthesizes Theorems 2 and 3 by providing a mild sufficiency condition (pertaining to $\Pi^{M}$ ) under which $\underline{\delta}<\delta^{M}$. Thus there typically exists a range of discount factors below $\delta^{M}$ for which we can completely characterize optimal collusion.

Theorem 4. Suppose $\Pi^{M}>c+\Delta c D\left(p_{H}^{*}\right)$. Then there exists a $\underline{\delta}<\delta^{M}$ charactered by lemma 3 such that, for each $\delta \in\left[\underline{\delta}, \delta^{M}\right], \underline{\Pi}(\delta)=0$ and the unique Pareto-optimal stationary equilibrium profit vector $\left(\Pi^{*}, \Pi^{*}\right)$ satisfies

$$
\Pi^{*}=(1-\delta)\left(2 \Pi^{*}-\Delta c D\left(p^{*}\left(\Pi^{*}\right)\right)\right)
$$

Further, $\Pi^{*}$ is continuous, strictly greater than $\Pi^{C}$, and strictly increasing in $\delta$. Finally, $\delta^{M}$ is characterized by

$$
\delta^{M}=\frac{\Pi^{M}-\Delta c D\left(p_{H}^{*}\right)}{2 \Pi^{M}-\Delta c D\left(p_{H}^{*}\right)},
$$

and perfect collusion is sustainable for all $\delta \geq \delta^{M}$.

For $\delta<\underline{\delta}$, we cannot guarantee that a continuation payoff of zero is sustainable in an SPNE. Whenever $\underline{\Pi}(\delta)>0$, maximum sustainable collusive payoffs fall below the level just characterized by Theorem 4. However, Theorem 2 continues to characterize those payoffs even for discount factors below $\underline{\delta}$, given $\underline{\Pi}(\delta)$.

Finally, we describe the on-path properties of a stationary equilibrium that supports the profit level $\Pi^{*}$. This construction is valid regardless of $\underline{\Pi}(\delta){ }^{22}$

Theorem 5. When $\delta<\delta^{M}$, maximal lifetime profits $\left(\Pi^{*}, \Pi^{*}\right)$ are supported by a stationary equilibrium with the following on-path properties:

1. The home firm's strategy is the same in each market, as is the away firm's.

2. The home firm always enters, while the away firm enters with probability strictly between 0 and 1.

\footnotetext{
${ }^{22}$ The theorem applies even if $\underline{\Pi}(\delta)=\Pi^{C}$, i.e. when Nash reversion is the harshest sustainable punishment. However in this case the equilibrium described by the theorem is simply unconditional repetition of the stagegame Nash equilibrium. This result is consistent with the conclusion of Theorem 2 that supra-competitive profits are sustainble iff punishments harsher than Nash reversion are sustainable.
} 
3. The home firm makes stage profits $\Pi^{*}$, while the away firm makes zero profits.

4. Each firm's price distribution has full support on $\left[p^{*}\left(\Pi^{*}\right), p_{H}^{*}\right]$ and is continuous on $\left(p^{*}\left(\Pi^{*}\right), p_{H}^{*}\right)$. The home firm places atoms at $p^{*}\left(\Pi^{*}\right)$ and $p_{H}^{*}$, while the away firm's price distribution is continuous.

5. The away firm makes sales with strictly positive probability, which is decreasing in $\Pi^{*}$.

6. Deviations by the away firm to prices at or below $p^{*}\left(\Pi^{*}\right)$ trigger a punishment that provides the deviating firm with a continuation payoff of $\underline{\Pi}(\delta)$.

The on-path strategies of this equilibrium are unique among all stationary equilibria for which price distributions have full support on $\left[p^{*}\left(\Pi^{*}\right), p_{H}^{*}\right]$ in each market.

We interpret this equilibrium as follows. The firms agree to an efficient division of demand with each firm serving its home market, along with an aspirational collusive price (specifically, the monopoly price), which the home firm often charges. However, because both firms recognize that the aspirational price is not fully sustainable $\left(\delta<\delta^{M}\right)$, they anticipate competitive raids, price cutting, and business stealing. To limit the impact of the inevitable episodes of competition, they also implicitly or explicitly establish a price floor (or minimum price) that is strictly less than the monopoly price $\left(p^{*}\left(\Pi^{*}\right)<p_{H}^{*}\right)$ and, if quoted by the home firm, ensures a win. The cartel cannot stop away firms from raiding markets and attempting to steal business at prices strictly between the price floor $p^{*}\left(\Pi^{*}\right)$ and the aspirational collusive price $p_{H}^{*}$, and consequently they tolerate such activity as part of the optimal collusive agreement. However, they do not tolerate defections to prices below the floor - such defections trigger punishment.

Comparing this equilibrium to a clean division of the market at the same minimum price yields some surprising observations, in that the firms' profits are identical, while consumers are worse off in the equilibrium (because prices are higher on average). In that sense, business stealing hurts consumers but not firms.

A clean division of the market with prices set at $p^{*}\left(\Pi^{*}\right)$ is much simpler than the equilibrium described in Theorem 5, so why don't the firms agree to that plan instead? The reason is that it is not an equilibrium. Each firm would have an incentive not only to raid its away market, but also to raise the price in its home market. Because all available punishment power is required to deter raids in the away market, the cartel must counter the incentive to raise price in the home market by allowing the away firm to enter with positive probability, charging a price greater than $p^{*}\left(\Pi^{*}\right)$. Entry by the away firm is costly, so it 
must also be incentivized. The incentives cannot come from punishments because, once again, punishment power is already fully deployed to deter raiding. (For a formalization of this point, see Theorem 7 below.) Instead, the cartel must allow the away firm to win the market some of the time.

\subsection{The inevitability of business stealing in imperfect cartels}

We have shown that there is an optimal (profit-maximizing) stationary equilibrium in which behavior interpretable as business stealing occurs with positive probability and goes unpunished. However, we have not shown that this optimal equilibrium is unique. In fact, there exist many optimal equilibria in which firms' price distributions do not have full support on $\left[p^{*}\left(\Pi^{*}\right), p_{H}^{*}\right]$. One can construct such equilibria by "drilling holes" in the full-support distribution of Theorem 5. As long as the holes are sufficiently small, the away firm will earn greater short-term profits by undercutting $p^{*}\left(\Pi^{*}\right)$ than by deviating into the hole, and hence this modification will not tighten the incentive-compatibility constraints.

In light of this multiplicity, it is important to determine whether unpunished business stealing is merely a special feature of certain optimal stationary equilibria, such as the one we exhibited in Theorem 5. On the contrary, as we demonstrate next, it is in fact a general feature; indeed, all optimal stationary equilibria involve (weakly) more business stealing than the one identified in Theorem 5. The following theorem establishes that result, and shows that other properties of the aforementioned equilibrium are also general.

Theorem 6. When $\delta<\delta^{M}$, all stationary equilibria supporting profits $\left(\Pi^{*}, \Pi^{*}\right)$ feature the same minimum price, maximum price, and entry probabilities by each firm in each market. In particular, the home firm always enters while the away firm enters with a fixed probability strictly between 0 and 1. Furthermore, among all stationary equilibria supporting profits $\left(\Pi^{*}, \Pi^{*}\right)$, the equilibrium characterized in Theorem 5 uniquely minimizes the probability that an away firm wins business.

It is also natural to wonder whether our conclusions extend to settings in which firms collude but fail to optimize cartel agreements. Remarkably, under some additional assumptions, when unpunished business stealing occurs in optimal cartels, it is also an inevitable feature of sub-optimal cartels.

As a general matter, any stationary equilibrium supporting profits close to $\left(\Pi^{*}, \Pi^{*}\right)$ must involve business stealing. For intuition, consider a stationary equilibrium yielding lifetime profits $(\Pi, \Pi)>\left(\Pi^{C}, \Pi^{C}\right)$, and assume that the firms stay out of each others' home markets so that no business stealing occurs. The most profitable deviation for each firm is to charge 
$p_{H}^{*}$ in its home market while slightly undercutting $p^{*}(\Pi)$ in its away market. This potential deviation is unprofitable only if the following incentive-compatibility constraint holds:

$$
\Pi \geq(1-\delta)\left(\Pi-\Delta c D\left(p^{*}(\Pi)\right)+\Pi^{M}\right)+\delta \underline{\Pi}(\delta) .
$$

In light of the fact that $\Pi^{*}<\Pi^{M}$, this constraint is plainly violated for $\Pi=\Pi^{*}$. Thus, by continuity of $D(\cdot)$ and $p^{*}(\cdot)$, there exists some $\widetilde{\Pi}<\Pi^{*}$ at which the constraint is just saturated, and above which it is necessarily violated. This result is formalized by the following theorem:

Theorem 7. Fix $\delta<\delta^{M}$. Then there exists a $\widetilde{\Pi}<\Pi^{*}$ such that, under any stationary equilibrium supporting profits $\left(\Pi_{1}, \Pi_{2}\right)>(\widetilde{\Pi}, \widetilde{\Pi})$, the away firm captures each market with strictly positive probability on the equilibrium path.

The key insight for this result is that, if perfect collusion is unsustainable, then in any cartel without business stealing each firm would be tempted to increase the price in its home market while undercutting its competitor in its away market. To sustain imperfect collusion, the firms must structure their agreement so as to dampen the incentive to raise price in the home market, which they can accomplish by introducing competition at higher prices. To incentivize such competition, the home firm must cede sufficient business for the away firm to cover entry costs; it accomplishes this objective by occasionally charging a high price that permits the away firm to prevail. Thus in equilibrium we have both occasional price escalation by the home firm and unpunished business stealing by the away firm.

\section{The case of many competitors}

Our simple duopoly model has the implication that perfect collusion is possible even for relatively low values of $\delta$ (in particular, $\delta^{M}<1 / 2$ from Theorem 4). If one interprets $\delta$ literally, i.e., as reflecting discounting at the market interest rate over the intervals between competitive interactions, then one would typically expect to find $\delta>\delta^{M}$ in practical applications, in which case the firms would achieve perfect collusion, and the structure of optimal collusive agreements for $\delta<\delta^{M}$ would have little bearing on actual cartel behavior.

However, one can also interpret $\delta$ more expansively (and less literally) as a reduced-form stand-in for other factors that tend to make firms focus more on present opportunities and less on future consequences. For example, in many simple models of oligopoly, the number of competitors affects the feasibility of collusion through the same channel as discounting 
(because adding firms increases the potential gains from current deviations and reduces the future benefits of cooperation). Firms may also effectively discount future profits to a greater extent than market interest rates would imply because of agency problems, leadership turnover, uncertainty about future market conditions, or capital market imperfections that raise internal hurdle rates.

In this section we explore the implications of multiple competitors explicitly. We show that collusion indeed becomes more difficult to sustain as the cartel size increases, and that perfect collusion is infeasible even with a moderate number of firms and discount factors close to unity. We also generalize the theorems of Section 4 and, for discount factors below $\delta^{M}$, provide a characterization of optimal collusion that is broadly similar to the two-firm case. Our results thus provide some reassurance that our central insights concerning cartels are robust with respect to the introduction of additional factors that make collusion more difficult to sustain.

\subsection{Setup}

We extend our model to many-firm settings while retaining symmetry across firms: there are now $N+1$ firms and $N+1$ markets, where $N \geq 2$. Firm $i$ 's marginal cost is $c_{H}$ for units sold in market $i$ (its home market), and $c_{A}>c_{H}$ for units sold elsewhere. All other features of the model are unchanged.

\subsection{Analyzing the stage game}

First consider a single round of the stage game played in isolation. Because payoffs are additively separable across markets, we can focus on play in a single market. Let $\{H\} \cup \mathscr{I}$ be the set of firms, where $H$ is the home firm and $\mathscr{I}=\{1, \ldots, N\}$ includes the away firms. The existence of a two-firm equilibrium implies that there are many Nash equilibria when $N \geq 2$. For if $H$ and any firm $i \in \mathscr{I}$ play the two-firm equilibrium, no away firm will have an incentive to enter (as it would receive strictly less than $i$ 's profits, which are zero). Hence there are at least $N$ Nash equilibria involving competition among pairs of firms.

In fact, for any non-empty subset of away firms, there is a Nash equilibria in which those firms compete with the home firm. Our main result establishes a limit on the multiplicity of equilibria: once a subset of away firms is chosen, there exists a unique Nash equilibrium involving participation by those firms. The form of this equilibrium is broadly similar to the two-firm equilibrium, with certain entry by the home firm, occasional entry by the away firms, and all firms randomly choosing prices between $\underline{p}_{A}$ and $p_{H}^{*}$, . Further, the equilibrium is 
symmetric in that all away firms play identical strategies. The following theorem summarizes these results:

Theorem 8. Fix any non-empty subset $\mathscr{J} \subset \mathscr{I}$ of away firms. Then there exists a unique Nash equilibrium of the stage game in which every firm in $\mathscr{J}$ enters with positive probability and no firm in $\mathscr{I} \backslash \mathscr{J}$ ever enters. In this equilibrium:

1. The home firm always enters and makes profits $\Pi_{H}=\Delta c D\left(\underline{p}_{A}\right)$.

2. Each away firm $i \in \mathscr{J}$ enters with probability strictly less than 1 and makes profits $\Pi_{i}=0$.

3. Each entering firm's price distribution has full support on $\left[\underline{p}_{A}, p_{H}^{*}\right]$.

4. All entering away firms play the same strategy.

There are no other Nash equilibria.

\subsection{Market-symmetric equilibrium}

When many firms compete, the set of possible collusive arrangements is much richer than with only two firms. For the latter case, we have seen that it is always optimal to allocate production so that each firm earns all of its profits in its home market. In contrast, with three or more firms, it can be worthwhile to spread each firm's profits across several markets; this reduces the profitability of undercutting in each market and thereby relaxes incentive constraints (in some instances).

In the Appendix, we describe an equilibrium which, for particular choices of $c, \Delta c$, and $\delta$, Pareto-dominates the best equilibrium in which firms earn profits only in their home markets. Table 1 displays the division of profits for the special case of three firms. The table includes a row for each firm and a column for each market; a "+" indicates positive profits while 0 indicates zero profits.

\begin{tabular}{c|ccc} 
& M1 & M2 & M3 \\
\hline F1 & + & 0 & 0 \\
F2 & + & + & 0 \\
F3 & 0 & 0 & +
\end{tabular}

Table 1: A division of equilibrium profits that is not market-symmetric 
With no further restrictions on the structure of the equilibrium, it is difficult to characterize optimal collusion. Note, however, that the equilibrium depicted in Table 1 has a feature that is arguably peculiar: within one of the markets (M1), ex ante identical away firms (F2 and F3) do not earn the same profits. It is reasonable to assume that symmetrically situated firms are drawn to symmetric agreements because they are easier to describe, likely simpler to negotiate, and require less coordination than asymmetric ones.

Given the asymmetry between home and away firms, an equilibrium for this model cannot be entirely symmetric. However, one can restrict attention to agreements that treat symmetrically situated firms within any given market symmetrically:

Definition 2. Fix a stationary equilibrium $\sigma$ with associated on-path stage-game strategy profile $\tau$. Then $\sigma$ is market-symmetric if, for each market $m$ and all away firms $i$ and $j$, $\tau_{m}^{i}=\tau_{m}^{j}$

Market-symmetric equilibria are stationary equilibria with an additional property: all the away firms play the same way in a given market. ${ }^{23}$ That property rules out profit profiles such as the one shown in Table 1. It does not, however, rule out the possibility that the behavior of the away firms differs across markets. Because all stationary equilibria are trivially market-symmetric when there are only two firms, imposing market symmetry disturbs none of our results for the case of duopoly. At the same time, it adds sufficient structure for us to characterize optimal collusion with more than two firms.

\subsection{Optimal market-symmetric equilibria}

We begin our analysis of optimal market-symmetric equilibria by introducing some additional notation. Recall that $\Pi^{M}$ is the monopoly profit of a low-cost provider in a single market. Let $\widetilde{\Pi}^{M}$ be the profit of a high-cost provider setting the same price $p_{H}^{*}$, which satisfies $\Pi^{M}-\widetilde{\Pi}^{M}=\Delta c D\left(p_{H}^{*}\right)>0$. (Note that $\widetilde{\Pi}^{M}$ is not the monopoly profit of the high-cost provider, as in general $p_{A}^{*}>p_{H}^{*}$.) With this notation, define

$$
\delta^{M}(N) \equiv 1-\frac{1}{N+1}\left(\frac{N}{N+1} \frac{\widetilde{\Pi}^{M}}{\Pi^{M}}+\frac{1}{N+1}\right)^{-1}
$$

The notation suggests that $\delta^{M}(N)$ is the minimal discount factor for which perfect collusion is sustainable with $N+1$ firms, a fact we establish later, under some conditions, in Theorem

\footnotetext{
${ }^{23}$ Alternatively, one could impose the weaker assumption that all away firms' profits have the same sign that is, either they all make strictly positive profits, or they all make zero profits. This alternative definition of market symmetry would yield identical results.
} 
12. Note that $\Pi^{M}>\widetilde{\Pi}^{M}$ implies that $\delta^{M}(N)<1-1 /(N+1)$.

Another useful discount factor threshold is $\bar{\delta}(N) \equiv\left(1-\frac{1}{N}\right)\left(1+\frac{c}{\Pi^{M}}\right)$. This expression plays an important role in our results and we will explain it shortly; for the moment, simply note that it is greater than $1-1 / N$ and may be either larger or smaller than $\delta^{M}(N)$. Finally, let $\underline{\Pi}(\delta ; N)$ be the minimum SPNE-sustainable lifetime profits with discount factor $\delta$ and $N+1$ firms.

Our first theorem generalizes Theorem 2:

Theorem 9. Suppose $\delta<\delta^{M}(N)$ and either $N \geq \sqrt{1+\Pi^{M} / c}$ or $\delta<\bar{\delta}(N)$. Then there exists a unique Pareto-optimal market-symmetric equilibrium payoff vector $\left(\Pi^{*}, \ldots, \Pi^{*}\right)$, where $\Pi^{*}$ satisfies

$$
\Pi^{*}=(1-\delta)\left((N+1) \Pi^{*}-\Delta c N D\left(p^{*}\left(\Pi^{*}\right)\right)\right)+\delta \underline{\Pi}(\delta ; N) .
$$

Further, $\Pi^{*}>\Pi^{C}$ iff $\underline{\Pi}(\delta ; N)<\Pi^{C}$, and $\Pi^{*}$ is strictly increasing in $\delta$ whenever $\underline{\Pi}(\cdot ; N)$ is nonincreasing in $\delta$. Finally, $\Pi^{*}$ is strictly decreasing in $N$ whenever $\underline{\Pi}(\delta ; \cdot)$ is nonincreasing in $N$.

The substance of this theorem is identical to that of Theorem 2. In essence it tells us that, provided $\delta$ is not too high, optimal collusion involves allocating markets according to cost advantages. As the theorem shows, the characterization of maximum sustainable profits then depends on the most severe punishment, $\underline{\Pi}(\delta ; N)$, that firms can mete out following a deviation.

In contrast to the case of a duopoly, the optimality of allocating markets according to cost advantages is not guaranteed for all $\delta<\delta^{M}(N)$. We also require $\delta<\bar{\delta}(N)$, which rules out the possibility of achieving higher profits by allocating business only to away firms (while respecting market symmetry). In the Appendix, we show by way of example that such an arrangement can yield profits exceeding the level indicated in Theorem 9 when $\delta^{M}(N)>\delta \geq \bar{\delta}(N)$. Table 2 depicts the division of profits for this example (in which there are three firms).

\begin{tabular}{c|ccc} 
& M1 & M2 & M3 \\
\hline F1 & 0 & + & + \\
F2 & + & 0 & + \\
F3 & + & + & 0
\end{tabular}

Table 2: A cartel with all profits awarded to away firms

If $\delta^{M}(N)<\bar{\delta}(N)$, then the additional restriction in Theorem 9 is trivially satisfied. A sufficient condition for this inequality to hold is $N \geq \sqrt{1+\Pi^{M} / c}$, which is a lower bound on 
the number of competitors given the ratio of monopoly profits to market-specific fixed costs. Because this bound grows slowly in $\Pi^{M} / c$, it may be satisfied in practice. For instance, $\Pi^{M} / c=3$ implies $N \geq 2$ (which is true by assumption), while $\Pi^{M} / c=15$ implies $N \geq 4$. Even if fixed costs were a trivial portion of monopoly profits, say 1\%, the implied bound on $N$ would be only $N \geq 10$. Consequently, imposing $N \geq \sqrt{1+\Pi^{M} / c}$ (and hence $\left.\delta^{M}(N)<\bar{\delta}(N)\right)$ strikes us as reasonably innocuous.

Even without the aforementioned restriction on $N$, the case of $\bar{\delta}(N)<\delta^{M}(N)$ is demonstrably unimportant. In particular:

Theorem 10. $\left[\bar{\delta}(N), \delta^{M}(N)\right] \subset(1-1 / N, 1-1 /(N+1))$. Therefore if $\delta \in\left[\bar{\delta}(N), \delta^{M}(N)\right)$, then $\delta<\bar{\delta}(N+1)$ and $\delta>\delta^{M}(N-1)$.

This theorem tells us that $\delta \in\left[\bar{\delta}(N), \delta^{M}(N)\right)$ is a knife-edge case: add one more firm and we will have $\delta<\bar{\delta}(N+1)$, which means we can focus on cartel structures that allocate markets according to cost. Subtract one firm, and the resulting cartel can sustain perfect collusion. The size of the problematic interval $\left[\bar{\delta}(N), \delta^{M}(N)\right)$ is also at most $1 /(N(N+1))$, and so collapses rapidly with $N$. We therefore consider the possibility of alternative collusive structures (ones that allocate profits to away firms) a minor issue that we can safely ignore.

The next result generalizes Theorem 3:

Theorem 11. Whenever

$$
\delta \geq \underline{\delta}(N) \equiv\left(1-\frac{1}{N+1}\right)\left(1+\frac{N}{N+1} \frac{\Pi^{M}-\widetilde{\Pi}^{M}}{c}\right)^{-1}
$$

there exists an SPNE supporting lifetime profits of 0 for each firm, so that $\underline{\Pi}(\delta ; N)=0$.

The structure of the punishment equilibrium resembles the one used for duopolies, but it has an asymmetric element: the punishment for firm $i$ consists of a price war between $i$ and another firm, say $i+1$, in their respective markets. All other firms stay out of those markets and play the stage-game Nash equilibrium in the remaining markets. Firms revert to cooperation after one round of a successful price war. Note that $\underline{\delta}(N)$ is increasing in $N$, but is strictly bounded away from 1 given $\Pi^{M}>\widetilde{\Pi}^{M}$. Thus even with a large number of somewhat impatient competitors, minmax punishments are feasible.

Next we generalize Theorem 4, and fully characterize optimal collusive payoffs for a range of discount factors below $\delta^{M}(N)$ under mildly restrictive conditions: 
Theorem 12. Suppose $\Pi^{M}>\Delta c D\left(p_{H}^{*}\right)+\frac{c}{N}$ and $N \geq \sqrt{1+\Pi^{M} / c}$. Then $\underline{\delta}(N)<\delta^{M}(N)<$ $\bar{\delta}(N)$, and for all $\delta \in\left[\underline{\delta}(N), \delta^{M}(N)\right]$ the unique Pareto-optimal market-symmetric equilibrium profit vector $\left(\Pi^{*}, \ldots, \Pi^{*}\right)$ satisfies

$$
\Pi^{*}=(1-\delta)\left((N+1) \Pi^{*}-\Delta c N D\left(p^{*}\left(\Pi^{*}\right)\right)\right) .
$$

Further, $\Pi^{*}$ is continuous, strictly greater than $\Pi^{C}$, and strictly increasing in $\delta$. Finally, $\delta^{M}(N)$ is the minimal discount factor at which perfect collusion is sustainable.

As in Theorem 4, we impose a mild sufficiency condition on $\Pi^{M}$ to ensure $\underline{\delta}(N)<\delta^{M}(N)$. This condition grows weaker as $N$ increases, and is trivially satisfied for sufficiently large $N$. Note that Theorem 12 does not directly speak to the form of $\Pi^{*}$ for any discount factor when $\bar{\delta}(N)<\delta^{M}(N)$. To address this deficiency, in Theorem B.7 of the Appendix we derive a very mild lower bound on $N$ that ensures $\underline{\delta}(N)<\bar{\delta}(N)$, in which case Theorem 12 continues to characterize optimal profits for discount factors in the range $[\underline{\delta}(N), \bar{\delta}(N))$.

Finally, we characterize an equilibrium supporting profits $\Pi^{*}$ for each firm. As in the case of a duopoly, this construction holds regardless of the value of $\underline{\Pi}(\delta ; N)$.

Theorem 13. Suppose $\delta<\delta^{M}(N)$. Then lifetime profits $\left(\Pi^{*}, \ldots, \Pi^{*}\right)$ are supported by a market-symmetric equilibrium with the following properties:

1. The home firm's strategy is the same in all markets, and all away firms play the same strategy in all markets.

2. The home firm enters with probability 1, while all away firms enter with a probability that is strictly between zero and 1 and decreasing in $\Pi^{*}$.

3. The home firm earns profits $\Pi^{*}$, while all away firms make zero profits.

4. Each firm posts prices only in $\left[p^{*}\left(\Pi^{*}\right), p_{H}^{*}\right]$, and firms' price distributions have full support on $\left(p^{*}\left(\Pi^{*}\right), p_{H}^{*}\right)$.

5. If $\Pi^{*}>\Delta c D\left(\underline{p}_{A}\right)$, the home firm plays $p^{*}\left(\Pi^{*}\right)$ with some strictly positive probability, which is increasing in $\Pi^{*}$.

6. Each market is captured by an away firm with some strictly positive probability, which is strictly decreasing in $\Pi^{*}$ when $\Pi^{*} \geq \frac{1}{2} \Pi^{M}$.

7. Any unilateral deviation by an away firm to a price at or below $p^{*}\left(\Pi^{*}\right)$ is punished by a continuation payoff of $\underline{\Pi}(\delta ; N)$ to that firm. 
This result mirrors our conclusions concerning the optimal collusive structure for a duopoly, and features business-stealing for essentially the same reason.

\subsection{Imperfect collusion in large cartels}

The following theorem explores how the range of discount factors for which we have characterized optimal collusion changes with cartel size.

Theorem 14. $\underline{\delta}(N)$ and $\delta^{M}(N)$ are strictly increasing in $N$, and $\lim _{N \rightarrow \infty} \underline{\delta}(N)<1$ while $\lim _{N \rightarrow \infty} \delta^{M}(N)=1$. Further, $\delta^{M}(N)-\underline{\delta}(N)$ is strictly increasing in $N$ whenever $\delta^{M}(N) \geq$ $\underline{\delta}(N)$.

Because $\delta^{M}(N)$ goes to 1 as $N$ grows large, large cartels can aspire only to imperfect collusion even when their members are extremely patient. The minimal discount factor required to sustain a price war yielding zero profits also grows with $N$, but more slowly. Thus the range of discount factors for which we completely characterize optimal collusion expands with $N$. Accordingly, this theorem establishes the robustness of our results with respect to cartel size. It also illustrates the point that our analysis of imperfect collusion applies in settings where firms' discount rates are in line with market interest rates.

\subsection{Comparative statics}

Our results rely on the presence of both a cost asymmetry $\Delta c$ between home and away firms, and a recurring fixed cost $c$ of attempting to serve a market. To illuminate the roles of both $\Delta c$ and $c$, we examine the limiting behavior of optimal collusion as each becomes small. We first consider the outcome when the cost asymmetry between firms declines to zero.

Theorem 15. Fix $\delta \in(0,1)$. As $c_{A} \downarrow c_{H}, \Pi^{*} \rightarrow \Pi^{C}$ if $\delta<N /(N+1)$ while $\Pi^{*} \rightarrow \Pi^{M}$ if $\delta \geq N /(N+1)$.

In the limit as $\Delta c$ shrinks to zero, the set of stationary market-symmetric equilibria exhibits a bang-bang structure. No collusion is possible for $\delta$ below the critical threshold $N /(N+1)$, while perfect collusion is sustainable for $\delta$ above that threshold. Thus, there is no room for imperfect collusion in the limit.

In contrast, with asymmetric costs, the degree of sustainable collusion rises gradually with the discount factor. As a cartel tries to become more collusive, the ratio of the profits gained by a deviating away firm when it undercuts a home firm rises relative to the profits earned by the home firm. Undercutting therefore becomes more tempting as the cartel 
tries to sustain higher profits. Accordingly, sustaining a slightly higher profit level requires slightly greater patience.

We can also examine the nature of collusion in the limit as the fixed cost of attempting to serve a market declines to zero.

Theorem 16. Fix $\delta \in(0,1)$. Let $\left(F_{H}^{*}(\cdot), F_{A}^{*}(\cdot), \pi_{A}^{*}\right)$ be the home and away firms' price distributions and the away firm's entry probability, respectively, for the equilibrium characterized in Theorem 13. As $c \rightarrow 0$,

- $F_{H}^{*}(\cdot)$ converges uniformly to $\mathbf{1}\left\{p \leq \underline{p}_{A}\right\}$,

- $\pi_{A} \rightarrow 1-\left(\Pi^{*} / \Pi^{M}\right)^{1 / N}$,

- $F_{A}^{*}(\cdot)$ converges uniformly to $\frac{1-\left(\frac{\Pi^{*}}{D(p)\left(p-c_{H}\right)}\right)^{1 / N}}{1-\left(\Pi^{*} / \Pi^{M}\right)^{1 / N}}$ on $\left[\underline{p}_{A}, p_{H}^{*}\right]$.

The probability of business stealing therefore falls to zero as c vanishes, and in the limit the home firm wins the market at price $\underline{p}_{A}$ with probability 1.

This theorem tells us that a nonzero market-specific fixed cost is crucial for generating equilibrium business stealing. Without it, away firms could costlessly set their prices just above $\underline{p}_{A}$, thereby deterring the home firm from charging higher prices without actually undercutting it. As we have discussed previously, in our model these fixed costs give rise to equilibrium business stealing because they preclude the firms from costlessly policing the cartel agreement. ${ }^{24}$

\section{Conclusion}

An important empirical feature of many real-world cartels is that deliberate cheating not only occurs, but also goes unpunished. Existing theories of collusion in repeated games cannot account for these observations because they predict that cheating will not occur, and that - if it did occur - it would trigger a pice war or some other punishment. We have attempted to bridge this gap between theory and practice by constructing a theory of equilibrium business stealing in imperfect cartels. Our theory concerns settings in which

\footnotetext{
${ }^{24}$ Theorem 16 sidesteps the issue of whether whether $\Pi^{*}$ as characterized by Theorem 12 is indeed the optimal collusive outcome in the limit $c \downarrow 0$. As $\underline{\delta}(N) \downarrow 0$ in this limit, the only potential issue is whether $\bar{\delta}(N) \geq \delta^{M}(N)$. Indeed, the sufficient condition $N \geq \sqrt{1+\Pi^{M} / c}$ is clearly not satisfied in the limit. However, a sharper sufficient condition may be derived by evaluating $\bar{\delta}(N)-\delta^{M}(N)>0$ at $c=0$, which yields the lower bound $N>\left(p_{H}^{*}-c_{H}\right) / \Delta c$. So for sufficiently large $N$, or for $N=1$, Theorem 12 indeed characterizes optimal (stationary, market-symmetric) profits as $c \downarrow 0$.
} 
different firms have natural advantages in serving different market segments, and where there is some recurring fixed cost of attempting to serve each segment; moreover, we focus on conditions under which some collusion is sustainable but perfect collusion is not.

We find that, within an important class of equilibria, optimal collusion necessarily entails business stealing. Moreover, the equilibria that sustain optimal collusion look very much like imperfectly enforced cartel agreements with aspirational prices, price floors, and customer allocations. Cartel members attempt to divide the market according to firms' cost advantages. Each firm often charges the aspirational price in its home market, but also sometimes engages in defensive price cutting down to and including the price floor (at which it is assured of winning the market) to head off "raids" by competitors. Firms sometimes attempt to raid each others' markets, in all such cases setting prices above the floor, so as to avoid stealing business if the home firm has made the "safe" choice. If, however, the home firm has also set a price above the floor, the rival may successfully steal business in a raid. Business stealing at prices above the floor occurs in equilibrium and is met with forbearance because all firms understand that they cannot fully sustain the aspirational collusive price.

Critically, according to our theory, not all business stealing is created equal. The cartel would harshly punish business stealing at prices below the floor, and consequently firms never deliberately trigger such punishments in equilibrium. In contrast, business stealing at prices above the floor is not merely tolerated, but is indeed critical for the cartel's successful operation. This stark divide between acceptable and unacceptable business stealing would become blurred in an extended model with imperfect monitoring, e.g., if undercutting were sometimes instigated by rogue sales personnel with no direct knowledge of or involvement in the cartel. Nonetheless, a robust testable implication of our theory is that business stealing will trigger punishment less frequently at high prices than at low prices.

\section{References}

Abreu, Dilip, "On the Theory of Infinitely Repeated Games with Discounting," Econometrica, 1988, 56 (2), pp. 383-396.

- and Yuliy Sannikov, "An Algorithm for Two-player Repeated Games with Perfect Monitoring," Theoretical Economics, 2014. Forthcoming.

_, David Pearce, and Ennio Stacchetti, "Optimal cartel equilibria with imperfect monitoring," Journal of Economic Theory, 1986, 39 (1), pp. 251-269. 
_ , _ , and _ , "Toward a Theory of Discounted Repeated Games with Imperfect Monitoring," Econometrica, 1990, 58 (5), pp. 1041-1063.

Athey, Susan and Kyle Bagwell, "Optimal Collusion with Private Information," The RAND Journal of Economics, 2001, 32 (3), pp. 428-465.

_ and _, "Collusion with Persistent Cost Shocks," Econometrica, 2008, 76 (3), pp. 493540.

_ , _, and Chris Sanchirico, "Collusion and Price Rigidity," The Review of Economic Studies, 2004, 71 (2), pp. 317-349.

Bernheim, B. Douglas and Michael D. Whinston, "Multimarket Contact and Collusive Behavior," The RAND Journal of Economics, 1990, 21 (1), pp. 1-26.

Genesove, David and Wallace P. Mullin, "Testing Static Oligopoly Models: Conduct and Cost in the Sugar Industry, 1890-1914," The RAND Journal of Economics, 1998, 29 (2), pp. 355-377.

_ and _, "Rules, Communication, and Collusion: Narrative Evidence from the Sugar Institute Case," The American Economic Review, 2001, 91 (3), pp. 379-398.

Green, Edward J. and Robert H. Porter, "Noncooperative Collusion under Imperfect Price Information," Econometrica, 1984, 52 (1), pp. 87-100.

Harrington, Joseph E. and Andrzej Skrzypacz, "Private Monitoring and Communication in Cartels: Explaining Recent Collusive Practices," The American Economic Review, 2011, 101 (6), pp. 2425-2449.

Harrington, Joseph E., Jr., "How Do Cartels Operate?," Foundations and Trends in Microeconomics, 2006, 2 (1), pp. 1-105.

Levenstein, Margaret C. and Valerie Y. Suslow, "What Determines Cartel Success?," Journal of Economic Literature, 2006, 44 (1), pp. 43-95.

Mailath, George J., Ichiro Obara, and Tadashi Sekiguchi, "The Maximum Efficient Equilibrium Payoff in the Repeated Prisoners' Dilemma," Games and Economic Behavior, 2002, 40 (1), pp. 99-122.

Marshall, Robert C., Leslie M. Marx, and Lily Samkharadze, "Monopolization Conduct by Cartels," 2013. Unpublished. 
Porter, Robert H., "A Study of Cartel Stability: The Joint Executive Committee, 18801886," The Bell Journal of Economics, 1983, 14 (2), pp. 301-314.

Rahman, David, "The Power of Communication," 2014. Unpublished.

Rotemberg, Julio J. and Garth Saloner, "A Supergame-Theoretic Model of Price Wars during Booms," The American Economic Review, 1986, 76 (3), pp. 390-407.

\section{A Assumptions on the demand function}

We impose several technical regularity conditions on the demand function $D(p)$ throughout the paper. For $i \in\{H, A\}$, define $\underline{p}_{i} \equiv \inf \left\{p \quad: \quad D(p)\left(p-c_{i}\right) \geq c\right\}$ and $p_{i}^{*} \equiv$ $\sup \left\{\arg \max _{p} D(p)\left(p-c_{i}\right)\right\}$. Then we assume that $D(p)$ satisfies:

(A1) $\sup _{p} D(p)\left(p-c_{A}\right)>c$ and $\lim _{p \rightarrow \infty} D(p)\left(p-c_{H}\right)=0$.

(A2) $\inf \left\{p: D(p)\left(p-c_{A}\right)>c\right\}<\inf \left\{\arg \max _{p}\left\{D(p)\left(p-c_{H}\right)\right\}\right\}$.

(A3) $D(p)\left(p-c_{H}\right)$ is strictly increasing on $\left[c_{H}, p_{H}^{*}\right]$.

Assumptions (A1) through (A3) are jointly sufficient to establish several facts:

(1) The monopoly profits of firm $i \in\{H, A\}$ are positive and strictly increasing on $\left[\underline{p}_{i}, p_{H}^{*}\right]$. Further, they are continuous on $\left[\underline{p}_{i}, p_{H}^{*}\right)$.

(2) The home firm's monopoly profits are strictly lower above $p_{H}^{*}$ than at $p_{H}^{*}$.

(3) Away firms' monopoly profits are strictly negative below $\underline{p}_{A}$.

(Proof that (A1) through (A3) imply these facts is straightforward and omitted.) These facts will be used freely in the proofs without explicit justification.

\section{B Core theorems}

In this Appendix we prove a sequence of general results for an arbitrary number of firms (i.e. $N \geq 1$ ), which imply most of the theorems in the text. In Appendices $\mathrm{C}$ and $\mathrm{D}$ we explicitly connect the theorems of the text to results proved here, as well as establish the few additional theorems which do not follow from the developments here. 


\section{B.1 The stage game}

Consider a market with $N+1$ firms, $N \geq 1$, consisting of a home firm $H$ and $N$ away firms $i \in \mathscr{I}=\{1, \ldots, N\}$.

Theorem B.1. Fix any non-empty subset $\mathscr{J} \subset \mathscr{I}$ of away firms. Then there exists a unique Nash equilibrium of the stage game in which every firm in $\mathscr{J}$ enters with positive probability and no firm in $\mathscr{I} \backslash \mathscr{J}$ ever enters. In this equilibrium:

1. The home firm always enters and makes profits $\Pi_{H}=\Delta c D\left(\underline{p}_{A}\right)$.

2. Each away firm $i \in \mathscr{J}$ enters with probability strictly less than 1 and makes profits $\Pi_{i}=0$.

3. Each entering firm's price distribution has full support on $\left[\underline{p}_{A}, p_{H}^{*}\right]$.

4. All entering away firms play the same strategy.

There are no other Nash equilibria.

Proof. Let $\left(\pi_{H}, F_{H},\left\{\pi_{i}, F_{i}\right\}_{i \in \mathscr{I}}\right)$ be a Nash equilibrium of the stage game. Define $\mathscr{J} \equiv\{i \in$ $\left.\mathscr{I}: \pi_{i}>0\right\}$. We first establish that at least one away firm must occasionally enter in equilibrium

Lemma B.1. $\mathscr{J}$ is non-empty.

Proof. If no away firm entered, then each away firm makes zero profits in equilibrium. Meanwhile, the unique profit-maximizing strategy of the home firm is to post price $p_{H}^{*}$. But then each away firm can make strictly positive profits by pricing just under $p_{H}^{*}$, a contradiction of equilibrium.

Define $\Pi_{i}(p)$ to be the expected profits of firm $i \in\{H\} \cup \mathscr{J}$ upon entering and setting price $p$ given the equilibrium strategies of all other firms. We will often overload notation by letting $\Pi_{i}$ (with no argument) represent the equilibrium profits of firm $i$.

The next lemma establishes that $\Pi_{i}(p)$ is continuous at $p$ iff no other firm places an atom at $p$, and that when an atom exists the profit function is discontinuous from both directions.

Lemma B.2. $\Pi_{i}(p-) \geq \Pi_{i}(p) \geq \Pi_{i}(p+)$ for all $i \in\{H\} \cup \mathscr{J}$ and $p \in\left[\underline{p}_{A}, p_{H}^{*}\right]$, with equality for given firm $i$ iff no other firm places an atom at $p$.

Proof. Obvious. 
The next lemma establishes that firms set prices only in the interval $\left[\underline{p}_{A}, p_{H}^{*}\right]$, that the home firm always enters the market, and that the away firm occasionally enteres the market.

Lemma B.3. $F_{H}\left(\left[\underline{p}_{A}, p_{H}^{*}\right]\right)=F_{i}\left(\left[\underline{p}_{A}, p_{H}^{*}\right]\right)=1$ for all $i \in \mathscr{J}$ and $\pi_{H}=1$.

Proof. Each $i \in \mathscr{J}$ receives strictly negative profits below $\underline{p}_{A}$ no matter the other firms' strategies. So $F_{i}\left(\underline{p}_{A}-\right)=0$ in equilibrium. Then the home firm is never profit-maximizing below $\underline{p}_{A}$ given that his profits are non-positive below $\underline{p}_{H}$, zero at $\underline{p}_{H}<\underline{p}_{A}$, and strictly increasing on $\left[\underline{p}_{H}, \underline{p}_{A}\right]$. Hence $F_{H}\left(\underline{p}_{A}-\right)=0$ as well. Additionally, the home firm achieves strictly positive profits by setting a price just below $\underline{p}_{A}$, so his equilibrium profits must be strictly positive and therefore $\pi_{H}=1$.

At the other end of the price support, the home firm always makes strictly lower profits setting a price above $p_{H}^{*}$ than by pricing at $p_{H}^{*}$, no matter the away firms' strategies. Then $F_{H}\left(p_{H}^{*}\right)=1$. This result, combined with the fact that the home firm always enters the market, means that any away firm pricing above $p_{H}^{*}$ will make no sale and achieve negative profits. This is less profitable than not entering the market, so $F_{i}\left(p_{H}^{*}\right)=1$ for each $i \in \mathscr{J}$ in equilibrium.

We next establish a "no overlapping atoms" result:

Lemma B.4. For each $p \in\left[\underline{p}_{A}, p_{H}^{*}\right]$, there exists at most one firm in $\{H\} \cup \mathscr{J}$ whose price distribution is not continuous at $p$.

Proof. Suppose some firm $i \in\{H\} \cup \mathscr{J}$ places an atom at $p \in\left(\underline{p}_{A}, p_{H}^{*}\right]$. Then $i$ must be profit-maximizing at $p$. If some other firm also placed an atom at $p$, then the limit of $i$ 's profits for prices just below $p$ would be strictly higher than his profits at $p$, by the previous lemma. This contradicts the optimality of $p$ for $i$, so no other firm can have an atom at $p$.

Finally, consider placement of an atom at $\underline{p}_{A}$ by two firms. At least one of these firms must be an away firm; but as the away firm loses the market with positive probability at that price, he makes strictly negative profits given the definition of $\underline{p}_{A}$. This means $\underline{p}_{A}$ cannot be optimal for that firm, ruling out the placement of an atom there. Reaching a contradiction, we conclude that at most one firm can place an atom at $\underline{p}_{A}$.

Let $\bar{p}_{i} \equiv \sup \left\{p: F_{i}(p)<1\right\}$ be the supremum of firm $i$ 's price support for $i \in\{H\} \cup \mathscr{J}$, and similarly let $\underline{p}_{i} \equiv \inf \left\{p: F_{i}(p)>0\right\}$ be the infimum.

Lemma B.5. $\bar{p}_{i}=p_{H}^{*}$ for all $i \in\{H\} \cup \mathscr{J}$. 
Proof. We first show that $\bar{p}_{i}=\bar{p}_{j}$ for all $i, j \in\{H\} \cup \mathscr{J}$. Suppose $\bar{p}_{i}>\max _{j \neq i} \bar{p}_{j} \equiv \bar{p}_{-i}$ for some $i \in\{H\} \cup \mathscr{J}$. As $i$ makes non-negative equilibrium profits, he must win with strictly positive probability when playing any price (strictly) above $\bar{p}_{-i}$. Thus his profits are strictly increasing on $\left(\bar{p}_{-i}, p_{H}^{*}\right]$, meaning $i$ places an atom at $p_{H}^{*}$ and does not set prices in $\left(\bar{p}_{-i}, p_{H}^{*}\right)$.

Now, if no atom existed at $\bar{p}_{-i}$, then some firm $j$ whose support supremum lies at $\bar{p}_{-i}$ has continuous profits there. Hence $\bar{p}_{-i}$ must be profit-maximizing for $j$. In particular, as $j$ makes non-negative profits, he wins with positive probability by pricing at $\bar{p}_{-i}$, so also by setting prices in $\left[\bar{p}_{-i}, p_{H}^{*}\right)$. But then $j$ 's profits are also strictly increasing on $\left[\bar{p}_{-i}, p_{H}^{*}\right)$, a contradiction.

Then it must be that some firm, say $j$ again, places an atom at $\bar{p}_{-i}$. But by the overlapping atoms result no other firm can place an atom there. Then $j$ 's profits are strictly increasing on $\left[\bar{p}_{-i}, p_{H}^{*}\right)$, contradicting the optimality of $\bar{p}_{-i}$ for $j$ implied by his placement of an atom there. We conclude that every firm's price ceiling is the same, say $\bar{p}$.

Suppose $\bar{p}<p_{H}^{*}$. If no firm places an atom at $\bar{p}$, then each firm's profits are continuous at $\bar{p}$ and hence this price is profit-maximizing for all firms. For equilibrium profits to be non-negative, each firm must win the market with positive probability at $\bar{p}$, meaning profits are strictly increasing on $\left[\bar{p}, p_{H}^{*}\right]$, a contradiction of optimality. So some firm $i$ must place an atom at $\bar{p}$, which is then profit-maximizing for $i$. Since there can be no overlapping atoms, $i$ 's profits are continuous at $\bar{p}$, meaning they are strictly increasing on $\left[\bar{p}, p_{H}^{*}\right]$, another contradiction. Hence $\bar{p}=p_{H}^{*}$.

Lemma B.6. $\underline{p}_{i}=\underline{p}_{A}$ and $\Pi_{i}=D\left(\underline{p}_{A}\right)\left(\underline{p}_{A}-c_{i}\right)-c$ for all $i \in\{H\} \cup \mathscr{J}$.

Proof. Suppose $\underline{p}_{i}<\min _{j \neq i} \underline{p}_{j} \equiv \underline{p}_{-i}$ for some $i$. Then $i$ wins w.p. 1 on $\left[\underline{p}_{i}, \underline{p}_{-i}\right]$, meaning his profits are strictly increasing on this interval. This contradicts the optimality of prices strictly less than $\underline{p}_{-i}$. Hence $\underline{p}_{i}=\underline{p}$ for some $\underline{p} \in\left[\underline{p}_{A}, p_{H}^{*}\right]$ and all $i \in\{H\} \cup \mathscr{J}$.

Suppose some firm placed an atom at $\underline{p}$. Then every other firm's profits at $\underline{p}$ are strictly higher than at prices just above $\underline{p}$, meaning no other firm's price distribution assigns positive measure to $(\underline{p}, \underline{p}+\varepsilon)$ for $\varepsilon>0$ sufficiently small. But given the definition of $\underline{p}$, this means every other firm must place an atom at $\underline{p}$, contradicting the overlapping atom result.

So there exist no atoms at $\underline{p}$, meaning by continuity of the profit function there that each firm's profits are maximized at $\underline{p}$. Hence $\Pi_{i}=D(\underline{p})\left(\underline{p}-c_{i}\right)-c$ for all $i$. Suppose $\underline{p}>\underline{p}_{A}$. Then $\Pi_{i}>0$ for all $i$, meaning $\pi_{i}=1$ for each $i$. Now consider the possible existence of an atom at $\bar{p}=p_{H}^{*}$. At most one firm can place an atom there, say firm $i$. Then $i$ is profit-maximizing at $p_{H}^{*}$, but given sure entry by all other participating firms below this price, $i$ makes $-c<0$ there, a contradiction. So no firm places an atom at $p_{H}^{*}$. But then each firm's profits are 
continuous at $p_{H}^{*}$, meaning given the definition of $\bar{p}$ that each firm's profits are maximized there. But their profits are again $-c<0$ there, another contradiction. So we must have $\underline{p}=\underline{p}_{A}$.

Lemma B.7. There can exist at most one atom in equilibrium, by the home firm at $p_{H}^{*}$.

Proof. Suppose some firm $i$ places an atom at $p \in\left[\underline{p}_{A}, p_{H}^{*}\right)$. Then there exists an $\varepsilon>0$ such that each firm $j \neq i$ places no support on $[p, p+\varepsilon)$. Now, we know that $i$ has profit-maximizing prices arbitrarily close to $p_{H}^{*}$ given that this is the supremum of his price support. Then $i$ wins with positive probability arbitrarily close to $p_{H}^{*}$, meaning he must win with (constant) positive probability on $\left[p, p+\varepsilon\right.$ ) (assuming $p+\varepsilon<p_{H}^{*}$, which we can assume wlog by taking $\varepsilon$ small). But then $i$ 's profits are strictly increasing on $[p, p+\varepsilon)$. This contradicts the fact that $p$ is profit-maximizing for $i$ implied by his placement of an atom there. So no such atom exists.

The existence of at most a single atom at $p_{H}^{*}$ follows from the overlapping atoms result. If this atom were placed by an away firm, the fact that $\pi_{H}=1$ implies that the away firm never wins the market at $p_{H}^{*}$ and thus that his profits are $-c<0$ there. This contradicts the optimality of $p_{H}^{*}$ implied by placement of an atom there. Hence only the home firm can place an atom at $p_{H}^{*}$.

Lemma B.8. $F_{H}$ has full support on $\left[\underline{p}_{A}, p_{H}^{*}\right]$.

Proof. Suppose not. Then there exists a non-degenerate open interval $S \subset\left(\underline{p}_{A}, p_{H}^{*}\right)$ assigned zero measure under $F_{H}$. Let $\widehat{F} \equiv F_{H}(p)$ for any $p \in S$. Because the infimum and supremum of the support of $F_{H}$ are $\underline{p}_{A}$ and $p_{H}^{*}$, we must have $\widehat{F} \in(0,1)$. Expand $S$ so that $S=\left(p_{L}, p_{H}\right)$, where $p_{L} \equiv \inf \left\{p: F_{H}(p)=\widehat{F}\right\}$ and $p_{H} \equiv \sup \left\{p: F_{H}(p)=\widehat{F}\right\}$. Because $\widehat{F} \in(0,1)$, each of $p_{L}$ and $p_{H}$ is finite and lies in $\left[\underline{p}_{A}, p_{H}^{*}\right]$. Also, by assumption $p_{L}<p_{H}$.

Because no other firm can place an atom at $p_{L}$ or $p_{H}$, the home firm's profits are continuous at these prices, and therefore both prices are profit-maximizing for him given $\widehat{F} \in(0,1)$. Then no price in $S$ can provide higher profits than at one of the endpoints. This implies the inequalities

$$
D(p)\left(p-c_{H}\right) \prod_{j \in \mathscr{J}}\left(1-\pi_{j} F_{j}(p)\right) \leq D\left(p_{H}\right)\left(p_{H}-c_{H}\right) \prod_{j \in \mathscr{J}}\left(1-\pi_{j} F_{j}\left(p_{H}\right)\right) \forall p \in S,
$$

with the lhs and rhs being $H$ 's profits at $p$ and $p_{H}$ respectively. (Recall that no away firm 
places an atom in $S$.) Now multiply each side by $\frac{p-c_{A}}{p-c_{H}} \frac{1-\pi_{H} F_{H}(p)}{1-\pi_{i} F_{i}(p)}$ for $i \in \mathscr{J}$. Then we obtain

$$
\begin{aligned}
& D(p)\left(p-c_{A}\right) \prod_{j \neq i}\left(1-\pi_{j} F_{j}(p)\right) \\
\leq & D\left(p_{H}\right)\left(p_{H}-c_{H}\right) \frac{p-c_{A}}{p-c_{H}} \frac{1-\pi_{H} F_{H}(p)}{1-\pi_{i} F_{i}(p)} \prod_{j \in \mathscr{J}}\left(1-\pi_{j} F_{j}\left(p_{H}\right)\right) \\
< & D\left(p_{H}\right)\left(p_{H}-c_{H}\right) \frac{p_{H}-c_{A}}{p_{H}-c_{H}} \frac{1-\pi_{H} \widehat{F}}{1-\pi_{i} F_{i}\left(p_{H}\right)} \prod_{j \in \mathscr{J}}\left(1-\pi_{j} F_{j}\left(p_{H}\right)\right) \\
= & D\left(p_{H}\right)\left(p_{H}-c_{A}\right)\left(1-\pi_{H} \widehat{F}\right) \prod_{j \in \mathscr{J} \backslash\{i\}}\left(1-\pi_{j} F_{j}\left(p_{H}\right)\right) .
\end{aligned}
$$

The second inequality follows from the fact that $\left(p-c_{A}\right) /\left(p-c_{H}\right)$ is strictly increasing in $p$, $1-\pi_{H} F_{H}(p)$ is constant, and $1-\pi_{i} F_{i}(p)$ is (weakly) decreasing in $p$ on $S$. We arrive at the inequalities

$$
D(p)\left(p-c_{A}\right) \prod_{j \neq i}\left(1-\pi_{j} F_{j}(p)\right)<D\left(p_{H}\right)\left(p_{H}-c_{A}\right)\left(1-\pi_{H} \widehat{F}\right) \prod_{j \in \mathscr{J} \backslash\{i\}}\left(1-\pi_{j} F_{j}\left(p_{H}\right)\right) \forall p \in S .
$$

The lhs are $i$ 's profits for $p \in S$ (recall that no firm places on atom in $S$ ). Meanwhile the rhs are $i$ 's profits in the limit for prices just below $p_{H}$. (No away firm places an atom at $p_{H}$.) Thus no price in $S$ can be profit-maximizing for $i$, as there is always some price very close to $p_{H}$ which will do better. So $i$ 's price distribution assigns zero measure to $S$ as well.

This reasoning holds for all $i$, so we conclude that no firm plays in $S$. As no firm places an atom at $p_{L}$, the home firm's profits are then strictly increasing on $\left[p_{L}, p_{H}\right)$, contradicting the optimality of $p_{L}$. Hence no such interval $S$ can exist.

Lemma B.9. $F_{i}$ has full support on $\left[\underline{p}_{A}, p_{H}^{*}\right]$ for each $i \in \mathscr{J}$.

Proof. Suppose not. Then for some $i \in \mathscr{J}$ we can construct an $S=\left(p_{L}, p_{H}\right)$ as in the previous lemma. We know that the home firm's price distribution has full support in this interval; if no other away firm played in $S$, then the home firm's profits would be strictly increasing in $S$, a contradiction. We will show, however, that no other away firm will play in $S$, proving the result. If $|\mathscr{J}|=1$, then the result is trivial, so assume $|\mathscr{J}| \geq 2$.

It can't be the case that the home firm places an atom at $p_{H}$, for then neither this price nor any price just above it would be profit-maximizing for $i$. (Recall $\widehat{F}<1$, so $i$ must have profit-maximizing profit-maximizing prices arbitrarily close to $p_{H}$ from above.) Because no other firm places an atom at $p_{H}$, firm $i$ 's profits are continuous there and hence $p_{H}$ is 
profit-maximizing for $i$. Then

$$
D(p)\left(p-c_{A}\right) \prod_{j \neq i}\left(1-\pi_{j} F_{j}(p)\right) \leq D\left(p_{H}\right)\left(p_{H}-c_{A}\right) \prod_{j \neq i}\left(1-\pi_{j} F_{j}\left(p_{H}\right)\right) \forall p \in S .
$$

Choose $k \in \mathscr{J} \backslash\{i\}$. Multiplying both sides by $\frac{1-\pi_{i} F_{i}(p)}{1-\pi_{k} F_{k}(p)}$ yields

$$
\begin{aligned}
& D(p)\left(p-c_{A}\right) \prod_{j \neq k}\left(1-\pi_{j} F_{j}(p)\right) \\
\leq & D\left(p_{H}\right)\left(p_{H}-c_{A}\right) \frac{1-\pi_{i} F_{i}(p)}{1-\pi_{k} F_{k}(p)} \prod_{j \neq i}\left(1-\pi_{j} F_{j}\left(p_{H}\right)\right) \\
\leq & D\left(p_{H}\right)\left(p_{H}-c_{A}\right) \frac{1-\pi_{i} F_{i}\left(p_{H}\right)}{1-\pi_{k} F_{k}\left(p_{H}\right)} \prod_{j \neq i}\left(1-\pi_{j} F_{j}\left(p_{H}\right)\right) \\
= & D\left(p_{H}\right)\left(p_{H}-c_{A}\right) \prod_{j \neq k}\left(1-\pi_{j} F_{j}\left(p_{H}\right)\right) .
\end{aligned}
$$

The second inequality is strict whenever $F_{k}\left(p_{H}\right)>F_{k}(p)$, in which case the inequality implies $k$ 's profits at $p_{H}$ are strictly higher than at $p$. (Recall no firm places an atom at $p_{H}$.)

Suppose by way of contradiction that $F_{k}$ assigns positive measure to some subset of $S$. Then given continuity of $F_{k}$ there exists a $p \in S$ such that $p$ is profit-maximizing for $k$ and $F_{k}\left(p_{H}\right)>F_{k}(p)$. But the latter inequality implies that $k$ 's profits at $p$ are strictly lower than at $p_{H}$, a contradiction of profit-maximization. So $k$ assigns zero measure to $S$. This yields the desired contradiction.

It is an immediate consequence of the previous lemma that each firm's profits are equal to $\Pi_{i}=D\left(\underline{p}_{A}\right)\left(\underline{p}_{A}-c_{i}\right)-c$ for all $p \in\left[\underline{p}_{A}, p_{H}^{*}\right)$. For the lack of atoms implies continuity of profits at all such $p$, and the full support result implies a sequence of profit-maximizing prices converging to $p$.

We now construct the unique equilibrium for a given (arbitrary) non-empty subset $\mathscr{J} \subset$ $\mathscr{I}$ of entering away firms. In light of continuity of each $F_{i}$ below $p_{H}^{*}$, the profit-maximization condition on $\left[\underline{p}_{A}, p_{h}^{*}\right)$ is

$$
D\left(\underline{p}_{A}\right)\left(\underline{p}_{A}-c_{i}\right)-c=D(p)\left(p-c_{i}\right) \prod_{j \neq i}\left(1-\pi_{j} F_{j}(p)\right)-c
$$


for all $i \in\{H\} \cup \mathscr{J}$ and $p \in\left[\underline{p}_{A}, p_{H}^{*}\right)$. For $i=H$ this becomes

$$
\prod_{j \in \mathscr{J}}\left(1-\pi_{j} F_{j}(p)\right)=\frac{D\left(\underline{p}_{A}\right)\left(\underline{p}_{A}-c_{H}\right)}{D(p)\left(p-c_{H}\right)}
$$

Inserting into the condition for $i \in \mathscr{J}$ yields

$$
1-\pi_{i} F_{i}(p)=\frac{D\left(\underline{p}_{A}\right)\left(\underline{p}_{A}-c_{H}\right)}{c} \frac{p-c_{A}}{p-c_{H}}\left(1-\pi_{H} F_{H}(p)\right) .
$$

Hence, inserting back into the $i=H$ condition,

$$
\pi_{H} F_{H}(p)=1-\frac{c}{D\left(\underline{p}_{A}\right)\left(\underline{p}_{A}-c_{H}\right)} \frac{p-c_{H}}{p-c_{A}}\left(\frac{D\left(\underline{p}_{A}\right)\left(\underline{p}_{A}-c_{H}\right)}{D(p)\left(p-c_{H}\right)}\right)^{1 /|\mathscr{J}|} .
$$

As $\pi_{H}=1$, this pins down $F_{H}(p)$ for $p<p_{H}^{*}$. Note that $F_{H}(\cdot)$ is strictly increasing in $p$, as required. Further, $F_{H}\left(p_{H}^{*}-\right)<1$, so $H$ must place an atom at $p_{H}^{*}$.

We re-write $H$ 's mixing distribution in final form as

$$
F_{H}(p)=1-\left(\frac{c}{D(p)\left(p-c_{A}\right)}\right)\left(\frac{D(p)\left(p-c_{H}\right)}{D\left(\underline{p}_{A}\right)\left(\underline{p}_{A}-c_{H}\right)}\right)^{1-1 /|\mathscr{J}|}
$$

for $p<p_{H}^{*}$, with $F_{H}\left(\underline{p}_{A}\right)=0$ and $F_{H}\left(p_{H}^{*}\right)=1$.

Next, by inserting $F_{H}(\cdot)$ into the relationship between $F_{i}$ and $F_{H}$, we find that each away firm's mixing distribution satisfies

$$
\pi_{i} F_{i}(p)=1-\left(\frac{D\left(\underline{p}_{A}\right)\left(\underline{p}_{A}-c_{H}\right)}{D(p)\left(p-c_{H}\right)}\right)^{1 /|\mathscr{J}|} .
$$

Because $F_{i}$ must be continuous and equal to 1 at $p_{H}^{*}$, this pins down $\pi_{i}$ as

$$
\pi_{i}=1-\left(\frac{D\left(\underline{p}_{A}\right)\left(\underline{p}_{A}-c_{H}\right)}{D\left(p_{H}^{*}\right)\left(p_{H}^{*}-c_{H}\right)}\right)^{1 /|\mathscr{J}|}
$$

Solving for $F_{i}(\cdot)$ yields each away firm's mixing distribution. Note that all participating away firms play an identical strategy.

Finally, we must check that it is optimal for each non-participating away firm not to enter. But each away firm $i \in \mathscr{J}$ makes zero profits when playing any $p \in\left(\underline{p}_{A}, p_{H}^{*}\right)$ when faced with $|\mathscr{J}|-1$ other away firms. Then at each price $p>\underline{p}_{A}$, all non-participating firms 
make strictly lower profits than $i$ because they will occasionally lose the sale to $i$. Then no non-participating firm wants to enter above $\underline{p}_{A}$. And entering at $\underline{p}_{A}$ yields zero profits. So indeed it is optimal for all firms in $\mathscr{I} \backslash \mathscr{J}$ to refrain from entering. This completely characterizes all Nash equilibria of the stage game.

\section{B.2 The repeated game}

In each period $t=1,2, \ldots$, the stage game is duplicated $N+1$ times, with firm $i \in \mathscr{I}=$ $\{1,2, \ldots, N+1\}$ acting as the home firm in market $i$. Firms maximize expected discounted utility with common discount factor $\delta \in(0,1)$. We will let $\Pi_{m}^{i}(\cdot)$ represent firm $i$ 's intraperiod profit function in market $m$, with similar notation for strategies $\left(\pi_{m}^{i}, F_{m}^{i}\right)$. We overload notation by letting $\Pi_{m}^{i}$ (with no argument) denote $i$ 's equilibrium intra-period profits in market $m$.

Lemma B.10. In any stationary equilibrium, each firm earns identical intra-period profits for all on-path actions.

Proof. Because the same stage-game strategy profile is played in every period on-path, each firm's continuation value must be the same following every on-path action. Thus a firm will choose only on-path actions which maximize intra-period profits.

In what follows we will restrict to stationary equilibria in which off-path actions yield continuation profits weakly lower than the on-path continuation. This is without loss of generality, as any stationary equilibrium may be modified to one of this sort without affecting on-path strategies or payoffs.

Theorem B.2. Suppose that $\delta<\delta^{M}(N)$. Then if $N=1$ or $N \geq \sqrt{1+\Pi^{M} / c}$ or $\delta<\bar{\delta}(N)$, at most one firm earns positive intra-period profits in each market in every market-symmetric stationary equilibrium.

Proof. We first show that the existence of multiple firms making positive profits in a given market implies a minimally profitable deviation for each such firm.

Lemma B.11. Fix a stationary equilibrium yielding strictly positive intra-period profits to $2 \leq K \leq N+1$ firms $i_{1}, i_{2}, \ldots, i_{K} \in \mathscr{I}$ in market $m$. Then for each $i=i_{1}, \ldots, i_{K}$, stage profits are bounded above as

$$
\Pi_{m}^{i} \leq \frac{1}{K}\left(\Pi^{M}+c-\Delta c D\left(p_{A}^{*}\right) \mathbf{1}\{i \neq m\}\right)-c
$$


and there exists a deviation in market $m$ yielding intra-period profits of at least $K \Pi_{m}^{i}+(K-$ 1)c.

Proof. Wlog fix $m=1$. (It will not matter whether the home firm is one of the firms receiving positive profits.) As a first observation, we must have $\pi_{1}^{i_{k}}=1$ for all $k=1, \ldots, K$. For strictly positive intra-period profits in market 1 imply existence of an on-path action $a$ involving entry which gives strictly positive profits. Failing to enter yields lower intra-period profits and a lower continuation than playing $a$, so each firm must choose to enter w.p. 1.

Define $\bar{p}^{i} \equiv \sup \left\{p: F_{1}^{i}(p)<1\right\}$ for $i \in \mathscr{I}$. Then $\bar{p}^{i}$ is the supremum of the support of firm $i$ 's price distribution in market $1 . \bar{p}^{i}<\infty$ for $i=i_{1}, \ldots, i_{k}$ given (A1) and the fact that intra-period on-path profits are strictly positive for each such firm in market 1.

We claim that $\bar{p}^{i_{k}}=\bar{p}^{i^{\prime}}$ for all $k, k^{\prime} \in\{1, \ldots, K\}$. Suppose not, say $\bar{p}^{i_{1}}>\max _{k=2, \ldots, K} \bar{p}^{i_{k}} \equiv$ $\bar{p}^{i_{-1}}$. Then there exists an interval $\left[p_{A}, p_{B}\right] \subset\left(\bar{p}^{i_{-1}}, \bar{p}^{i_{1}}\right]$ such that $F_{1}^{i_{1}}\left(\left[p_{A}, p_{B}\right]\right)>0$. In particular, there exists a $p^{*} \in\left[p_{A}, p_{B}\right]$ such that $\Pi_{1}^{i_{1}}\left(p^{*}\right)=\Pi_{1}^{i_{1}}$. But given $\pi_{1}^{i_{k}}=1$ and $F_{1}^{i_{k}}\left(p^{*}\right)=1$ for all $k \geq 2$, we have $\Pi_{1}^{i_{1}}\left(p^{*}\right)=-c<0$, contradicting the assumption that $\Pi_{1}^{i_{1}}>0$.

Let $\bar{p}$ be the mutual supremum of the price supports for firms $i_{1}$ through $i_{K}$. We next argue that each of these firms places an atom at $\bar{p}$. Suppose that some firm, say $i_{1}$, places no atom at $\bar{p}$. Then each of $i_{2}$ through $i_{K}$ receive intra-period profits of $-c<0$ at $\bar{p}$ given that $\pi_{1}^{i_{1}}=1$. So none of these firms places an atom at $\bar{p}$ either. But then $\Pi_{1}^{i_{1}}(\bar{p}-)=-c$, since for prices approaching $\bar{p}$ firm $i_{1}$ will be underbid by one of $i_{2}$ through $i_{k}$ with probability approaching 1 . Then $i_{1}$ 's profits are non-positive for prices sufficiently close to $\bar{p}$, meaning they cannot be profit-maximizing. But then for some $\varepsilon>0$ the interval $[\bar{p}-\varepsilon, \bar{p}]$ is assigned measure zero by $F_{1}^{i_{1}}(\cdot)$, a contradiction of the definition of $\bar{p}$. So $i_{1}$ must place an atom at $\bar{p}$.

Now, the existence of overlapping atoms generates a profitable intra-period deviation for each firm. Consider the case of firm $i_{1}$. His equilibrium intra-period profits in market 1 are equal to his profits at $\bar{p}$, which are bounded above as

$$
\Pi_{1}^{i_{1}} \leq\left[\prod_{j \notin\left\{i_{1}, \ldots, i_{K}\right\}}\left(1-\pi_{j} F_{1}^{j}(\bar{p}-)\right)\right]\left[\prod_{k=2, . ., K} \Delta F_{1}^{i_{k}}(\bar{p})\right] \frac{1}{K} D(\bar{p})\left(\bar{p}-c_{i_{1}}\right)-c .
$$

(The inequality will be strict if some other firm also places an atom at $\bar{p}$.) This bound is loosest if no firms enter below $\bar{p}$ and the price ceiling is set to the profit-maximizing value for a given firm. This yields the upper bound in the lemma statement. 
Meanwhile, by deviating to just under $\bar{p}$ he can obtain profits of at least

$$
\widetilde{\Pi}_{1}^{i_{1}}=\left[\prod_{j \notin\left\{i_{1}, \ldots, i_{K}\right\}}\left(1-\pi_{j} F_{1}^{j}(\bar{p}-)\right)\right]\left[\prod_{k=2, . ., K} \Delta F_{1}^{i_{k}}(\bar{p})\right] D(\bar{p})\left(\bar{p}-c_{i_{1}}\right)-c \geq K \Pi_{1}^{i_{1}}+(K-1) c .
$$

This is the deviation claimed in the lemma statement.

Now, consider an arbitrary market-symmetric stationary equilibrium. Assume that in in some market, at least two firms earn positive profits.

The $N=1$ case: Assume both firms make positive profits in market 1 . There are two possibilities: either both firms earn positive profits in market 2 as well, or some firm $i$ earns non-positive profits. In the former case, firm $i$ has a deviation worth $2 \Pi_{m}^{i}+c$ in each market, which when summed imply the IC constraint

$$
\Pi^{i} \geq(1-\delta)\left(2 \Pi^{i}+2 c\right)
$$

(In fact, if the harshest punishment continuation is nonzero an even tighter IC constraint holds, but we won't need the tighter bound. A similar remark applies to other IC constraints in this proof.) In the latter case, firm $i$ has a deviation worth at least $2 \Pi_{1}^{i}+c$ in market 1 and $2 \Pi_{2}^{i}$ in market 2 (the latter following trivially from $\Pi_{2}^{i} \leq 0$ ), hence the IC constraint

$$
\Pi^{i} \geq(1-\delta)\left(2 \Pi^{i}+c\right)
$$

holds. In either case we must have $\Pi^{i} \geq(1-\delta) 2 \Pi^{i}$. Now, $\Pi^{i}>0$, else $i$ could deviate and obtain positive profits by exiting market 2 . So this inequality implies $\delta \geq 1 / 2>\delta^{M}(1)$.

The $N \geq 2$ case:

Lemma B.12. There exists a firm $i \in \mathscr{I}$ and an integer $n \in\{1, \ldots, N, N+1\}$ for which the IC constraint

$$
\Pi^{i} \geq(1-\delta)\left(N \Pi^{i}+n(N-1) c\right)
$$

holds, and $0<\Pi^{i} \leq \frac{n}{N}\left(\Pi^{M}-(N-1) c\right)$.

Proof. Suppose first that the home firm makes strictly positive profits in every market. Assume multiple firms make positive profits in market 1 . Then by market symmetry all $N+1$ firms make positive profits in that market, and firm 1 therefore has a deviation worth $(N+1) \Pi_{1}^{1}+N c$ in that market by the previous lemma. Additionally, in every other market $m \geq 2$ he either makes non-positive profits, and so trivially has a deviation worth $(N+1) \Pi_{1}^{1}$; 
or else he makes positive profits and has a deviation worth $(N+1) \Pi_{m}^{1}+N c$ in that market as well.

Summing the profits for firm 1 from deviating across all markets, assuming that 1 makes positive profits in $n-1$ markets other than his own, we obtain the IC constraint

$$
\Pi^{1} \geq(1-\delta)\left((N+1) \Pi^{1}+n N c\right)
$$

As $\Pi^{1}>0$ (else he could deviate by withdrawing from all markets $i \geq 2$ to make positive profits), this IC constraint implies the desired one.

Further, the previous lemma implies that his profits in each positive-profit market $m$ are at most

$$
\frac{1}{N+1}\left(\Pi^{M}+c-\Delta c D\left(p_{A}^{*}\right) \mathbf{1}\{m \geq 2\}\right)-c<\frac{\Pi^{M}}{N+1}-\frac{N}{N+1} c .
$$

Hence by making positive profits in $n$ markets, he can make no more than $\frac{n}{N+1}\left(\Pi^{M}-N c\right)$, implying the desired bound given that $N /(N+1)>(N-1) / N$.

Now suppose that the home firm makes non-positive profits in some market, say market 1. Then firm 1 must make positive profits in some other market $m \geq 2$, else he could deviate to achieve positive profits by undercutting in whatever market yields positive profits to multiple firms. In market $m$ all other away firms also make positive profits by marketsymmetry, hence 1 has a deviation worth $N \Pi_{m}^{1}+(N-1) c$. The same reasoning holds in all other markets in which he makes positive profits. And when he makes non-positive profits, he trivially has a deviation worth $N$ times his profits. Summing these deviations, assuming 1 makes positive profits in $n$ markets, we obtain the IC constraint

$$
\Pi^{1} \geq(1-\delta)\left(N \Pi^{1}+n(N-1) c\right)
$$

which is the desired one. Reasoning as in the previous case shows that he can make no more than $\frac{n}{N}\left(\Pi^{M}-(N-1) c\right)$.

Solving the IC constraint just derived for $\delta$, we require that

$\delta \geq 1-\frac{\Pi^{i}}{N \Pi^{i}+n(N-1) c} \geq 1-\frac{\frac{n}{N}\left(\Pi^{M}-(N-1) c\right)}{n\left(\Pi^{M}-(N-1) c\right)+n(N-1) c}=1-\frac{1}{N}\left(1-\frac{(N-1) c}{\Pi^{M}}\right)$.

This latter quantity is greater than $\delta^{M}(N)$ when

$$
1-\frac{(N-1) c}{\Pi^{M}} \leq \frac{1}{\frac{N+1}{N}-\frac{\Delta c D\left(p_{H}^{*}\right)}{\Pi^{M}}}
$$


As the rhs of this inequality is always greater than $N /(N+1)$, a sufficient condition is

$$
1-\frac{(N-1) c}{\Pi^{M}} \leq 1-\frac{1}{N+1} \Rightarrow N \geq \sqrt{1+\Pi^{M} / c} .
$$

Theorem B.3. Suppose $\delta<\delta^{M}(N)$ and $N=1$ or $N \geq \sqrt{1+\Pi^{M} / c}$ or $\delta<\bar{\delta}(N)$. Then payoffs $\left(\Pi^{1}, \ldots, \Pi^{N+1}\right)$ of any market-symmetric stationary equilibrium must satisfy $\Pi^{i} \in$ $\left[0, \Pi^{M}\right]$ and

$$
\Pi^{i} \geq(1-\delta)\left(\sum_{j=1}^{N+1} \Pi^{j}-\Delta c \sum_{j \neq i} D\left(p^{*}\left(\Pi^{j}\right)\right)\right)+\delta \underline{\Pi}(\delta ; N),
$$

for all $i \in \mathscr{I}$, where $p^{*}(\Pi)$ is the unique solution in $\left[\underline{p}_{H}, p_{H}^{*}\right]$ to $D(p)\left(p-c_{H}\right)-c=\Pi$ for $\Pi \in\left[0, \Pi^{M}\right]$.

Further, any such equilibrium yields strictly positive profits to each firm in at most one market. When $N \geq 2$, this market is the firm's home market.

Proof. Assume the conditions of the proposition statement, and fix a market-symmetric stationary equilibrium with profits $\left(\Pi^{1}, \ldots, \Pi^{N+1}\right)$. We must have $\Pi^{i} \geq 0$ for all $i$, else any firm earning negative profits could withdraw from all markets permanently as a profitable deviation.

Lemma B.13. Each firm $i \in \mathscr{I}$ can receive positive profits in at most one market.

Proof. Suppose some firm, say firm 1, received positive profits in two or more markets. Then by the pigeonhole principle, along with the fact that at most one firm can earn positive profits in any one market, there must be some firm $i \geq 2$ which receives non-positive profits in all markets and hence non-positive lifetime profits. But firm $i$ has a deviation yielding positive lifetime profits by undercutting the infimum of firm 1's price support in some market in which 1 is an away firm and makes positive profits. (Such a market exists by assumption.) So no firm can receive positive profits in multiple markets.

The lemma implies that each $\Pi^{i} \leq \Pi^{M}$, as this is the most any firm could make in a single market. So $p^{*}(\cdot)$ is well-defined over the range of profits allowable in equilibrium. Also, when $N \geq 2$ stage symmetry implies that firm $i$ 's positive-profit market must be his home market, else all other away firms would also make positive profits in that market.

Let $m(i)$ be the (unique) market in which firm $i \in \mathscr{I}$ receives positive profits. If $i$ receives positive profits in no market, choose $m(i)$ to be some market in which he receives 
zero profits. $m: \mathscr{I} \rightarrow \mathscr{I}$ can always be constructed so that it is a bijection, which we will assume in what follows.

Now consider the following deviation by firm $i$ : he follows his equilibrium strategy in market $i$, while for each $j \neq i$ firm $i$ just undercuts the infimum of firm $j$ 's price support in market $m(j)$. Because firm $j$ makes his entire profits $\Pi^{j}$ in market $m(j)$, his price support infimum must be at least $p^{*}\left(\Pi^{j}\right)$ there. Hence, since $D\left(p^{*}(\cdot)\right)$ is a decreasing function, $i$ makes at least $\Pi^{j}-\Delta c D\left(p^{*}\left(\Pi^{j}\right)\right)$ through undercutting in market $m(j)$. (He makes more from undercutting if the infimum of $j$ 's price support is larger than $p^{*}\left(\Pi^{j}\right)$, or if $m(j)$ is not j's home market, but we will not need to make use of this fact.)

Summing the intra-period profits from this deviation yields

$$
\sum_{j=1}^{N+1} \Pi^{j}-\Delta c \sum_{j \neq i} D\left(p^{*}\left(\Pi^{j}\right)\right)
$$

Thus, to deter a profitable deviation the IC constraint stated in the problem statement must hold.

Theorem B.4. Fix a profit vector $\left(\Pi^{1}, \ldots, \Pi^{N+1}\right) \in\left[\Delta c D\left(\underline{p}_{A}\right), \Pi^{M}\right]^{N+1}$ satisfying

$$
\Pi^{i} \geq(1-\delta)\left(\sum_{j=1}^{N+1} \Pi^{j}-\Delta c \sum_{j \neq i} D\left(p^{*}\left(\Pi^{j}\right)\right)\right)+\delta \underline{\Pi}(\delta ; N)
$$

for all $i \in \mathscr{I}$. Then there exists a market-symmetric stationary equilibrium supporting this profit vector with the following properties:

1. If $\Pi^{m}=\Pi^{m^{\prime}}$ for markets $m$ and $m^{\prime}$, then the home and away firms' strategies are the same in both markets.

2. The home firm in market $m$ enters with probability 1, while all away firms enter with a probability that is strictly between zero and 1 and decreasing in $\Pi^{m}$.

3. The home firm earns profits $\Pi^{m}$ in market $m$, while all away firms make zero profits.

4. Each firm posts prices only in $\left[p^{*}\left(\Pi^{m}\right), p_{H}^{*}\right]$ in market $m$, and firms' price distributions have full support on $\left(p^{*}\left(\Pi^{m}\right), p_{H}^{*}\right)$.

5. If $\Pi^{m}>\Delta c D\left(\underline{p}_{A}\right)$, the home firm in market $m$ plays $p^{*}\left(\Pi^{m}\right)$ with some strictly positive probability, which is increasing in $\Pi^{m}$. 
6. Each market where $\Pi^{m}<\Pi^{M}$ is captured by an away firm with some strictly positive probability, which is strictly decreasing in $\Pi^{m}$ when $\Pi^{m} \geq \frac{N-1}{2 N-1} \Pi^{M}-\frac{N}{2 N-1}$.

7. Any unilateral deviation by an away firm to a price at or below $p^{*}\left(\Pi^{m}\right)$ in any market $m$ is punished by a continuation payoff of $\underline{\Pi}(\delta ; N)$ to that firm.

Proof. We construct an equilibrium analogous to the stage-game, with a higher price floor. Fix a market $m$. If $\Pi^{m}=\Pi^{M}$, then the home firm plays $p_{H}^{*}$ w.p. 1 while the away firms do not enter. So assume $\Pi^{m}<\Pi^{M}$. The home firm mixes so as to make each away firm indifferent over prices in $\left(p^{*}\left(\Pi^{m}\right), p_{H}^{*}\right)$. The indifference condition, assuming symmetric play by all away firms, is

$$
0=D(p)\left(p-c_{A}\right)\left(1-\pi_{A} F_{A}(p)\right)^{N-1}\left(1-F_{H}(p)\right)-c .
$$

Meanwhile the away firms play to make the home firm indifferent over all prices in the same interval, yielding

$$
\Pi^{m}=D(p)\left(p-c_{H}\right)\left(1-\pi_{A} F_{A}(p)\right)^{N}-c .
$$

Hence

$$
\pi_{A} F_{A}(p)=1-\left(\frac{\Pi^{m}+c}{D(p)\left(p-c_{H}\right)}\right)^{1 / N},
$$

which when substituted into the away firm's indifference condition allows us to solve for $F_{H}(p)$ on $\left(p^{*}\left(\Pi^{m}\right), p_{H}^{*}\right)$ :

$$
F_{H}(p)=1-\frac{c}{D(p)\left(p-c_{A}\right)}\left(\frac{\Pi^{m}+c}{D(p)\left(p-c_{H}\right)}\right)^{1-1 / N} .
$$

In the limit as $p \searrow p^{*}\left(\Pi^{m}\right)$, we have

$$
F_{H}\left(p^{*}\left(\Pi^{m}\right)+\right)=1-\frac{c}{D\left(p^{*}\left(\Pi^{m}\right)\right)\left(p^{*}\left(\Pi^{m}\right)-c_{A}\right)}=1-\frac{c}{\Pi^{m}+c-\Delta c D\left(p^{*}\left(\Pi^{m}\right)\right)} .
$$

Then whenever $\Pi^{m}>\Delta c D\left(\underline{p}_{A}\right) \geq \Delta c D\left(p^{*}\left(\Pi^{m}\right)\right)$, this expression is strictly positive. So the home firm places an atom at $p^{*}\left(\Pi^{m}\right)$ of size

$$
\Delta F_{H}\left(p^{*}\left(\Pi^{m}\right)\right)=1-\frac{c}{\Pi^{m}+c-\Delta c D\left(p^{*}\left(\Pi^{m}\right)\right)}
$$

Note that $p^{*}(\cdot)$ is increasing while $D(\cdot)$ is decreasing, and hence $\Pi^{m}-\Delta c D\left(p^{*}\left(\Pi^{m}\right)\right)$ is strictly increasing in $\Pi^{m}$. Thus $\Delta F_{H}\left(p^{*}\left(\Pi^{m}\right)\right)$ is strictly increasing in $\Pi^{m}$. 
Further, as $p \nearrow p_{h}^{*}$ we have

$$
F_{H}\left(p_{H}^{*}-\right)=1-\frac{c}{\Pi^{M}+c-\Delta c D\left(p_{H}^{*}\right)}\left(\frac{\Pi^{m}+c}{\Pi^{M}+c}\right)^{1-1 / N},
$$

which is strictly less than 1 . So the home firm places another atom at $p_{H}^{*}$ of size

$$
\Delta F_{H}\left(p_{H}^{*}\right)=\frac{c}{\Pi^{M}+c-\Delta c D\left(p_{H}^{*}\right)}\left(\frac{\Pi^{m}+c}{\Pi^{M}+c}\right)^{1-1 / N} .
$$

Finally, we complete our characterization of the strategy played by all away firms. Note that $\pi_{A} F_{A}\left(p^{*}\left(\Pi^{m}\right)+\right)=0$, so the away firm's price distribution is continuous at its lower end. On the other hand,

$$
\pi_{A} F_{A}\left(p_{H}^{*}\right)=1-\left(\frac{\Pi^{m}+c}{\Pi^{M}+c}\right)^{1 / N}
$$

which is strictly positive. In order to avoid the away firm placing an atom at $p_{H}^{*}$ (which would not be optimal given the atom placed there by the home firm), we set

$$
\pi_{A}=1-\left(\frac{\Pi^{m}+c}{\Pi^{M}+c}\right)^{1 / N}
$$

which lies strictly between zero and 1 and is decreasing in $\Pi^{m}$.

Having exhibited a strategy profile in each market, we must show that it is supportable in equilibrium. The home firm has no profitable deviation in each market, while the away firms' most profitable deviation is to just below $p^{*}\left(\Pi^{m}\right)$, yielding profits $\Pi^{m}-\Delta c D\left(p^{*}\left(\Pi^{m}\right)\right)$. So each firm has $N$ profitable deviations in each market other than his own, and our strategies are an equilibrium iff the IC constraint stated in the proposition holds.

The fact that business-stealing occurs is immediate from the fact that the home and away firms play price distributions with overlapping support. To evaluate when it is decreasing in $\Pi^{m}$, we first compute the probability of business-stealing. The probability that some firm undercuts a given price $p$ is the complement of the probability that no firm does, which is $\left(1-\pi_{A} F_{A}(p)\right)^{N}$. Then, taking account of the atom by the home firm at $p_{H}^{*}$, we have

$\mathbb{P}\{$ Business stealing $\}=\left(1-\left(1-\pi_{A}\right)^{N}\right) \Delta F_{H}\left(p_{H}^{*}\right)+\int_{\left(p^{*}\left(\Pi^{m}\right), p_{H}^{*}\right)}\left(1-\left(1-\pi_{A} F_{A}(p)\right)^{N}\right) d F_{H}(p)$.

(The open-set notation for the limits of integration indicates that the atoms at the top and bottom of the support of $F_{H}(\cdot)$ are excluded from the integral.) 
Let $\widetilde{F}_{H}(p) \equiv \frac{F_{H}(p)}{\left(\Pi^{m}+c\right)^{1-1 / N}}$. Note that $\widetilde{F}_{H}(p)$ has the property that its increments are independent of $\Pi^{m}$. Now, inserting the expression for $\pi_{A} F_{A}(p)$ derived earlier, we obtain

$$
\begin{aligned}
& \mathbb{P}\{\text { Business stealing }\} \\
& =\left(\Pi^{m}+c\right)^{1-1 / N}\left(1-\frac{\Pi^{m}+c}{\Pi^{M}+c}\right) \Delta \widetilde{F}_{H}\left(p_{H}^{*}\right) \\
& \quad+\int_{\left(p^{*}\left(\Pi^{m}\right), p_{H}^{*}\right)}\left(\Pi^{m}+c\right)^{1-1 / N}\left(1-\frac{\Pi^{m}+c}{\Pi^{M}+c}\right) d \widetilde{F}_{H}(p) .
\end{aligned}
$$

Now we differentiate wrt $\Pi^{m}$, assuming that both $\widetilde{F}_{H}$ and $p^{*}$ are differentiable. (We will show later that this assumption is innocuous.) Differentiating wrt $\Pi^{m}$ in the limit of integration yields no contribution, as the integrand is zero at the lower limit. The remaining terms are then

$$
\begin{aligned}
& \frac{d}{d \Pi^{m}} \mathbb{P}\{\text { Business stealing }\} \\
= & \left(\Pi^{m}+c\right)^{-1 / N}\left[\left((1-1 / N)-(2-1 / N) \frac{\Pi^{m}+c}{\Pi^{M}+c}\right) \Delta \widetilde{F}_{H}\left(p_{H}^{*}\right)\right. \\
& \left.+\int_{\left(p^{*}\left(\Pi^{m}\right), p_{H}^{*}\right)}\left((1-1 / N)-(2-1 / N) \frac{\Pi^{m}+c}{D(p)\left(p-c_{H}\right)}\right) d \widetilde{F}_{H}(p)\right] .
\end{aligned}
$$

(Recall that the increments of $\widetilde{F}_{H}$ are not a function of $\Pi^{m}$.) Both the leading term and the integrand are negative over the entire integration range when

$$
\left((1-1 / N)-(2-1 / N) \frac{\Pi^{m}+c}{\Pi^{M}+c}\right) \leq 0,
$$

i.e. when

$$
\Pi^{m} \geq \frac{1-1 / N}{2-1 / N}\left(\Pi^{M}+c\right)-c=\frac{N-1}{2 N-1} \Pi^{M}-\frac{N}{2 N-1} c .
$$

Recall that we had assumed sufficient regularity to be able to differentiate wrt the lower limit of integration. In the general case, the increase in business stealing for small increase in $\Pi^{m}$ will be less than if we had assumed $p^{*}\left(\Pi^{m}\right)$ to be fixed, as the integrand is nonnegative and the integrator is increasing. Thus, an upper bound on the first-order change in business-stealing is the one just derived. Whenever that bound is negative, the change in business-stealing must also be negative for sufficiently small changes in $\Pi^{m}$. 
Theorem B.5. Assume $\delta<\delta^{M}(N)$. Among equilibrium payoff profiles satisfying

$$
\Pi^{i} \geq(1-\delta)\left(\sum_{j=1}^{N+1} \Pi^{j}-\Delta c \sum_{j \neq i} D\left(p^{*}\left(\Pi^{j}\right)\right)\right)+\delta \underline{\Pi}(\delta ; N),
$$

there is a unique profile simultaneously maximizing all firms' payoffs, namely $\left(\Pi^{*}, \ldots, \Pi^{*}\right)$, where $\Pi^{*}$ is the unique solution to

$$
\Pi=(1-\delta)\left((N+1) \Pi-\Delta c N D\left(p^{*}(\Pi)\right)\right)+\delta \underline{\Pi}(\delta ; N) .
$$

Further, for $N$ fixed $\Pi^{*}>\Pi^{C}$ iff $\underline{\Pi}(\delta ; N)<\Pi^{C}$, and $\Pi^{*}$ is strictly increasing in $\delta$ whenever $\underline{\Pi}(\cdot ; N)$ is non-increasing in $\delta$.

Proof. Fix a payoff profile $\left(\Pi^{1}, \ldots, \Pi^{N+1}\right)$ satisfying the IC constraints. Suppose the payoffs are not all equal, say $\Pi^{1}<\min _{i \geq 2} \Pi^{N+1}$. We claim there exists a Pareto-superior payoff profile satisfying the IC constraints.

Note that for each $i \geq 2, D\left(p^{*}\left(\Pi^{1}\right)\right) \geq D\left(p^{*}\left(\Pi^{i}\right)\right)$ and therefore

$$
-\sum_{j \neq i} D\left(p^{*}\left(\Pi^{j}\right)\right) \leq-\sum_{j \neq 1} D\left(p^{*}\left(\Pi^{j}\right)\right)
$$

Hence the rhs of the IC constraint is smaller for each firm $i \geq 2$ than it is for firm 1 . But the lhs is strictly larger for each other firm, so no firm's IC constraint can be binding except possibly firm 1's.

Now consider raising $\Pi^{1}$ by a small amount. This loosens 1's IC constraint, as the lhs rises by more than the rhs. Meanwhile, given continuity of $D(\cdot)$ and $p^{*}(\cdot)$ (the latter of which is easy to prove), a small change in $\Pi^{1}$ will not violate the slack IC constraints for any other firm. Hence there exists another payoff profile, giving slightly more profits to firm 1, which satisfies the IC constraints.

We conclude that any optimal payoff profile satisfying the IC constraints gives equal payoffs to all firms. Such a profile is subject to the single IC constraint

$$
\Pi \geq(1-\delta)\left((N+1) \Pi-\Delta c N D\left(p^{*}(\Pi)\right)\right)+\delta \underline{\Pi}(\delta ; N) .
$$

As $\delta<\delta^{M}(N)<1-1 /(N+1)$, raising $\Pi$ increases the rhs more quickly than the lhs. Hence, given continuity of the rhs, there exists a unique $\Pi$ for which the $\mathrm{IC}$ constraint just binds. This is the largest possible payoff satisfying the IC constraint. 
Finally, note that

$$
(N+1) \Pi-\Delta c N D\left(p^{*}(\Pi)\right) \geq(N+1) \Pi^{C}-\Delta c N D\left(p^{*}\left(\Pi^{C}\right)\right)=\Pi^{C},
$$

with equality when $\Pi=\Pi^{C}$. Thus $\Pi^{*}>\Pi^{C}$ iff $\underline{\Pi}(\delta ; N)<\Pi^{C}$. And since raising $\delta$ lowers the rhs of the IC constraint whenever $\Pi>\Pi^{C}$ and $\underline{\Pi}(\delta ; N)$ is decreasing in $\delta$, we conclude that $\Pi^{*}$ is increasing in $\delta$ whenever the latter condition holds.

Theorem B.6. Suppose that

$$
\delta \geq\left(1+\frac{1}{N}+\frac{\Pi^{M}-\widetilde{\Pi}^{M}}{c}\right)^{-1}
$$

Then for each firm $m$ there exists an SPNE supporting lifetime profits of 0 for firm $m$, so that $\underline{\Pi}(\delta ; N)=0$.

Proof. We explicitly construct such an equilibrium strategy profile. Wlog let $m=1$. The equilibrium consists of two phases: "punishment" and "cooperation." In the punishment phase, firm 1 enters his home market and prices at some $p^{P W} \leq \underline{p}_{H}$, while in market 2 he enters and mixes with any distribution assigning measure 1 to $\left(p^{P W}, \underline{p}_{H}\right]$. Firm 2 plays symmetrically in the two markets. All other firms stay out of markets 1 and 2 , and in all remaining markets all firms play the stage-game NE. In the cooperative phase firms play an SPNE yielding profits $\left(\Pi^{*}, \ldots, \Pi^{*}\right)$ characterized in Theorem B.5. Players transit from the punishment to the cooperative phase after a single stage, and stay in the cooperative phase forever. All deviations result in a reversion to the punishment phase.

We choose $p^{P W}$ so that lifetime profits for firms 1 and 2 are zero, implying

$$
(1-\delta)\left(D\left(p^{P W}\right)\left(p^{P W}-c_{H}\right)-2 c\right)+\delta \Pi^{*}=0
$$

In order that $p^{P W} \leq \underline{p}_{H}$ (crucial to preventing a profitable deviation yielding positive lifteime profits to firms 1 or 2 ), we therefore require

$$
\Pi^{*} \geq \frac{1-\delta}{\delta} c
$$

Now, $\Pi^{*}$ is characterized by

$$
\Pi^{*}=(1-\delta)\left((N+1) \Pi^{*}-\Delta c N D\left(p^{*}\left(\Pi^{*}\right)\right)\right)
$$


whenever the strategy profile outlined is indeed an equilibrium. Re-arranging yields

$$
\Pi^{*}=(1-\delta)\left((N+1) \Pi^{*}-\Delta c N D\left(p^{*}\left(\Pi^{*}\right)\right)\right) .
$$

Combining this expression with the lower bound on $\Pi^{*}$ derived earlier yields the bound

$$
\delta \geq\left(1+\frac{1}{N}+\frac{\Delta c D\left(p^{*}\left(\Pi^{*}\right)\right)}{c}\right)^{-1} .
$$

Our strategy profile satisfies $p^{P W} \leq \underline{p}_{H}$ iff this inequality holds. Now, note that $\Delta c D\left(p^{*}\left(\Pi^{*}\right)\right) \geq$ $\Delta c D\left(p_{H}^{*}\right)=\Pi^{M}-\widetilde{\Pi}^{M}$, so the inequality in the problem statement implies this one.

We complete the proof by checking that no firm has any profitable deviations. By construction no such deviations exist in the cooperation phase. As for the punishment phase, no firm has any profitable deviation in markets 3 through $N+1$ because the stage-game NE is played there. As for markets 1 and 2, firms 3 through $N+1$ could never win the market at a profitable price by entering, so they have no incentive to enter. As for firms 1 and 2, given $p^{P W} \leq \underline{p}_{H}$ their most profitable deviation is to exit both markets at once, yielding 0 in the current stage and a punishment continuation of 0 . This is precisely the same as their lifetime payoffs from playing their equilibrium strategies, so they have no profitable deviations.

We conclude that our proposed strategy profile is indeed an equilibrium whenever $p^{P W} \leq$ $\underline{p}_{H}$, and in particular whenever the inequality in the theorem statement holds.

Theorem B.7. Suppose $N \geq 1+\sqrt{\frac{\Pi^{M}-\widetilde{\Pi}^{M}}{c}}$. Then $\bar{\delta}(N)>\underline{\delta}(N)$.

Proof. As $\bar{\delta}(N)>1-1 / N$, a sufficient condition for $\bar{\delta}(N)>\underline{\delta}(N)$ is

$$
1-\frac{1}{N} \geq\left(1+\frac{1}{N}+\frac{\Pi^{M}-\widetilde{\Pi}^{M}}{c}\right)^{-1}
$$

Some rearrangement yields the equivalent inequality

$$
N(N-1) \geq \frac{\Pi^{M}-\widetilde{\Pi}^{M}}{c},
$$

which is in turn implied by

$$
(N-1)^{2} \geq \frac{\Pi^{M}-\widetilde{\Pi}^{M}}{c} .
$$

Solving for $N$ yields the inequality in the theorem statement. 


\section{Proofs of theorems for the two-firm case}

This section provides proofs of all theorems stated for the $N=1$ case (i.e. those of sections 3 and 4). The proofs rely heavily on general results developed in Appendix B.

Proof of Theorem 1. This is a special case of Theorem B.1.

Proof of Theorem 2. This result is a consequence of Theorems B.3 and B.5, specialized to the $N=1$ case. Theorem B.3 gives a necessary condition for a profit vector to be supportable as a market-symmetric stationary equilibrium, in the form of a set of inequalities. Theorem B.5 shows that these inequalities form a sufficient condition for existence of an equilibrium and characterizes the unique (Pareto-)optimal profit vector within the set of vectors satisfying the inequalities.

Proof of Theorem 3. This is a special case of Theorem B.6.

Proof of Theorem 4. Take $\delta^{M}$ as in the statement of the theorem. By construction, this discount factor satisfies

$$
\Pi^{M}=\left(1-\delta^{M}\right)\left(2 \Pi^{M}-\Delta c D\left(p^{*}\left(\Pi^{M}\right)\right)\right)
$$

Then so long as $\delta^{M}>\underline{\delta}$, the theorem follows from Theorems 2 and 3 . To establish this inequality, simply note that our expression for $\delta^{M}$ is increasing in $\Pi^{M}$, and at $\Pi^{M}=c+$ $\Delta c D\left(p_{H}^{*}\right)$ we have $\delta^{M}=\underline{\delta}$.

Proof of Theorem 5. This is a special case of Theorem B.4.

Proof of Theorem 6. Recall that by Theorem B.2 at most one firm can earn positive profits in a given market, and by Theorem B.3 each firm makes positive profits in only one market. Then the payoff vector $(\Pi, \Pi)$ (streamlining the notation $\Pi^{*}$ to $\Pi$ for this proof) can only be supported by giving each firm $\Pi$ in his home market and 0 in his away market. To see this, observe that it cannot be that each firm makes $\Pi$ in his away market; for this leads to a deviation worth $\Pi+\Delta c D\left(p^{*}(\Pi)\right)>\Pi-\Delta c D\left(p^{*}(\Pi)\right)$ in the home market, which violates the IC constraint. And we can rule out making negative profits in the away market, because this also increases the value of a deviation in that market and violates the IC constraint.

Now fix a market, say market 1. As firm 1 makes positive profits in this market, he enters w.p. 1. Further, firm 1 cannot have a profitable deviation in this market, else the IC constraint would be violated. 
We first claim that the support of firm 1's price distribution is contained in $\left[p^{*}(\Pi), p_{H}^{*}\right]$. Below $p^{*}(\Pi)$ he cannot earn profits $\Pi$, so such prices can't be profit-maximizing. Meanwhile above $p_{H}^{*}$ he will earn weakly lower profits than at $p_{H}^{*}$, with profits strictly lower whenever profits at $p_{H}^{*}$ are positive. Thus his profits above $p_{H}^{*}$ are either non-positive, thus not optimal, or else strictly lower than at $p_{H}^{*}$, which would introduce a profitable devition if 1 did play above $p_{H}^{*}$ in equilibrium.

Let $\underline{p}_{1}$ and $\bar{p}_{1}$ be the infimum and supremum of 1's price support. We claim that $\underline{p}_{1}=$ $p^{*}(\Pi)$ and $\bar{p}_{1}=p_{H}^{*}$. Suppose that $\underline{p}_{1}>p^{*}(\Pi)$. Then firm 2 has a deviation worth at least $D\left(\underline{p}_{1}\right)\left(\underline{p}_{1}-c_{A}\right)-c>\Pi-\Delta c D\left(p^{*}(\Pi)\right)$, violating the IC constraint. So the lower end of 1's support must be $p^{*}(\Pi)$. On the other hand, if $\bar{p}_{1}<p_{H}^{*}$, then 2 must place an atom at $\bar{p}_{1}$ to avoid giving 1 a profitable deviation up to $p_{H}^{*}$. If 1 doesn't place an atom at $\bar{p}_{1}$, then 2 never wins at $\bar{p}_{1}$ and thus makes negative profits there, which can't be profit-maximizing. But if he does place an atom at $\bar{p}_{1}$, then he would have a profitable deviation to just below the atom, a contradiction. Hence $\bar{p}_{1}=p_{H}^{*}$.

Now, suppose there exists an interval $\left[p_{L}, p_{H}\right] \subset\left[p^{*}(\Pi), p_{H}^{*}\right]$ such that $F_{1}^{1}\left(\left(p_{L}, p_{H}\right)\right)=0$. Let $\widehat{F}_{1}=F_{1}^{1}(p)$ for $p \in\left(p_{L}, p_{H}\right)$, and expand $\left[p_{L}, p_{H}\right]$ if necessary so that $p_{L}=\inf \{p$ : $\left.F_{1}^{1}(p)=\widehat{F}_{1}\right\}$ and $p_{H}=\sup \left\{p: F_{1}^{1}(p)=\widehat{F}_{1}\right\}$. Given the support of $F_{1}^{1}$, we must have $\widehat{F}_{1} \in(0,1)$. Thus 1 has profit-maximizing prices arbitrarily close to both $p_{L}$ and $p_{H}$.

Consider firm 2's strategy in $\left[p_{L}, p_{H}\right]$. He can set at most one price in $\left(p_{L}, p_{H}\right)$, since stage profits are strictly increasing in the interior of the interval. Say he plays some price $p^{*} \in\left(p_{L}, p_{H}\right)$ with positive probability. If he also places an atom at $p_{L}$, then 1 puts no atom there to avoid a profitable deviation. But then 2's stage profits at $p^{*}$ are strictly greater than at $p_{L}$, a contradiction. So 2 places no atom at $p_{L}$. But then $p_{L}$ must be profit-maximizing for 1 , a contradiction given that his profits are strictly increasing on $\left[p_{L}, p^{*}\right)$. So 2 does not play in $\left(p_{L}, p_{H}\right)$.

Firm 2 does play an atom at $p_{L}$, else 1 would have a profitable deviation into the gap. It follows that $p_{L}>p^{*}(\Pi)$ and 1 plays no atom there and is profit-maximizing in the limit as $p \nearrow p_{L}$. Conversely, firm 2 does not place an atom at $p_{H}$, for otherwise 1 would have a profitable deviation just below it. It follows that 1 is profit-maximizing at $p_{H}$.

From these facts we can pin down the size of firm 2's atom at $p_{L}$. Firm 1's profits from playing just below $p_{L}$ are

$$
\Pi=D\left(p_{L}\right)\left(p_{L}-c_{H}\right)\left(1-\pi_{1}^{2} F_{1}^{2}\left(p_{L}\right)+\frac{1}{2} \pi_{1}^{2} \Delta F_{1}^{2}\left(p_{L}\right)\right)-c
$$


while his profits at $p_{H}$ are

$$
\Pi=D\left(p_{H}\right)\left(p_{H}-c_{H}\right)\left(1-\pi_{1}^{2} F_{2}^{1}\left(p_{L}\right)\right)-c .
$$

Using the second equation to eliminate $F_{2}^{1}\left(p_{L}\right)$ from the first, we find that

$$
\pi_{1}^{2} \Delta F_{2}^{1}\left(p_{L}\right)=(\Pi+c)\left(\frac{1}{D\left(p_{L}\right)\left(p_{L}-c_{H}\right)}-\frac{1}{D\left(p_{H}\right)\left(p_{H}-c_{H}\right)}\right) .
$$

This is the probability that 2 enters and plays in $\left[p_{L}, p_{H}\right]$. It is easy to check that this is equal to the probability that firm 2 plays in $\left[p_{L}, p_{H}\right]$ under equilibrium characterized in Theorem 5. (We will refer to this equilibrium as the "standard equilibrium" or the "no-gap case" in what follows.)

Similarly, we may calculate the size of firm 1's atom at $p_{H}$. Suppose $p_{H}<p_{H}^{*}$. As firm 2 places an atom at $p_{L}$, he must be profit-maximizing there. Then

$$
0=D\left(p_{L}\right)\left(p_{L}-c_{A}\right)\left(1-F_{1}^{1}\left(p_{L}\right)\right)-c
$$

It is also true that firm 2 must be profit-maximizing arbitrarily close to $p_{H}$ from above. For otherwise he would not play in some interval above $p_{H}$, and firm 1 would have a profitable deviation upward from $p_{H}$. Then

$$
0=D\left(p_{H}\right)\left(p_{H}-c_{A}\right)\left(1-F_{1}^{1}\left(p_{L}\right)-\frac{1}{2} \Delta F_{1}^{1}\left(p_{H}\right)\right)-c
$$

So

$$
\Delta F_{1}^{1}\left(p_{H}\right)=c\left(\frac{1}{D\left(p_{L}\right)\left(p_{L}-c_{A}\right)}-\frac{1}{D\left(p_{H}\right)\left(p_{H}-c_{A}\right)}\right) .
$$

This is the same as the probability that firm 1 plays in $\left[p_{L}, p_{H}\right]$ under the standard equilibrium. If $p_{H}=p_{H}^{*}$ then we must modify the argument slightly: we still know $F_{1}^{1}\left(p_{L}\right)$, and now $F_{1}^{1}\left(p_{H}\right)=1$. This again determines the atom, which is easily checked to give the same probability of playing in $\left[p_{L}, p_{H}\right]$ under the standard equilibrium.

We conclude that, for any gap in firm 1's mixing distribution, both firms play in the gap with the same frequency as in the no-gap case, except that the away firm concentrates all its support at the bottom of the gap, while the home firm prices only at the top. Hence business-stealing is strictly higher in regions where gaps have been added.

Finally, in any interval with no gap, both firms must play the entry-adjusted mixing distributions of the standard equilibrium. So business-stealing occurs at the same rate in 
these regions as in the standard equilibrium. Finally, sum the probability of business-stealing across all gap- and no-gap intervals. (Formally: there are at most a countable number of maximally-sized gaps, which can be well-ordered by their upper edges. The no-gap regions are then defined as the intervals between the upper edge of one gap and the lower edge of the next. These are also countable, so can be summed.) This sum is strictly higher than the standard equilibrium when gaps exist, and the standard equilibrium is the unique no-gap equilibrium.

Proof of Theorem 7. Fix $\delta<\delta^{M}$, and consider a stationary equilibrium supporting profits $\left(\Pi^{1}, \Pi^{2}\right)>\left(\Pi^{C}, \Pi^{C}\right)$. Suppose wlog that in market 1, player 2 never wins the customer's business. Theorem B.3 says that player 1 earns positive profits only in that market, so $\Pi_{1}^{1} \geq \Pi^{1}$. And as player 2 never wins the business of that market, to earn total profits $\Pi^{2}$ it must be that $\Pi_{2}^{2} \geq \Pi^{2}$.

Now, suppose player 2 does not enter market 1 . Then player 1 can deviate upward to $p_{H}^{*}$ in his own market to earn stage profits $\Pi^{M}$, and can undercut player 2 in market 2 to earn $\Pi^{2}$. Thus the IC constraint

$$
\Pi^{1} \geq(1-\delta)\left(\Pi^{M}+\Pi^{2}-\Delta c D\left(p^{*}\left(\Pi^{2}\right)\right)\right)+\delta \underline{\Pi}(\delta)
$$

must hold. (If $\Pi_{2}^{2}>\Pi^{2}$ then an even stricter IC constraint holds.) Meanwhile, the usual IC constraint

$$
\Pi^{2} \geq(1-\delta)\left(\Pi^{1}+\Pi^{2}-\Delta c D\left(p^{*}\left(\Pi^{1}\right)\right)\right)+\delta \underline{\Pi}(\delta)
$$

holds for player 2. $\left(\Pi_{2}^{2}>\Pi^{2}\right.$ would imply that 2 makes negative profits in market 1 , which would only increase the profitability of a deviation and tighten the IC constraint.) Because $\Pi^{1}<\Pi^{M}$, the first constraint is violated at $\left(\Pi^{1}, \Pi^{2}\right)=\left(\Pi^{*}, \Pi^{*}\right)$. But the second constraint would be violated if $\Pi^{2}$ alone were lowered, as the lhs drops faster than the rhs and the constraint is saturated at $\left(\Pi^{*}, \Pi^{*}\right)$. Thus $\left(\Pi^{1}, \Pi^{2}\right)$ must be bounded below $\left(\Pi^{M}, \Pi^{M}\right)$ by continuity of $D(\cdot)$ and $p^{*}(\cdot)$ in order to satisfy both constraints.

On the other hand, suppose player 2 does enter market 1 . As he never wins the market by assumption, his stage profits in that market are $-c$. Then he must enter w.p. 1, else he would not be optimizing by entering. Player 2's IC constraint is the same no matter what he plays in market 1. Meanwhile, to maximally relax player 1's IC constraint, 2 may mix just above the single price $p_{1}$ played by player 1 in that market with sufficient density close to $p_{1}$ to deter an upward deviation. (Becuase 1 always wins, he can be cannot be willing to 
mix between multiple prices.) In this case player 1's IC constraint is the usual

$$
\Pi^{1} \geq(1-\delta)\left(\Pi^{1}+\Pi^{2}-\Delta c D\left(p^{*}\left(\Pi^{2}\right)\right)\right)+\delta \underline{\Pi}(\delta)
$$

But now player 2's deviation to undercut player 1 in market 1 yields additional profits of $c$, so his IC constraint is tightened to

$$
\Pi^{2} \geq(1-\delta)\left(\Pi^{1}+\Pi^{2}+c-\Delta c D\left(p^{*}\left(\Pi^{2}\right)\right)\right)+\delta \underline{\Pi}(\delta)
$$

By a similar argument to the previous case, solutions to this pair of inequalities are bounded below $\left(\Pi^{M}, \Pi^{M}\right)$.

\section{Proofs of theorems for the many-firm case}

This section provides proofs of all theorems stated for the $N \geq 2$ case (i.e. those of section 5 ). The proofs, as for the two-firm case, rely heavily on general results developed in Appendix B.

Proof of Theorem 8. This is a special case of Theorem B.1.

Proof of Theorem 9. This result is a consequence of Theorems B.3 and B.5. Theorem B.3 gives a necessary condition for a profit vector to be supportable as a market-symmetric stationary equilibrium (under the conditions of the theorem), in the form of a set of inequalities. Theorem B.5 shows that these inequalities form a sufficient condition for existence of an equilibrium and characterizes the unique (Pareto-)optimal profit vector within the set of vectors satisfying the inequalities.

Proof of Theorem 10. The set inclusion follows from the fact that $\delta^{M}(N)<1-1 /(N+1)$ while $\bar{\delta}(N)>1-1 / N$, inequalities which are obvious by inspection of the relevant definitions. The remaining inequalities are immediate corollaries of the fact that the collection of sets $S_{n}=(1-1 / N, 1-1 /(N+1))$ are pairwise disjoint.

Proof of Theorem 11. This is a special case of Theorem B.6.

Proof of Theorem 12. This result follows from Theorems 9 and 11, once we have established the chain of inequalities $\underline{\delta}(N)<\delta^{M}(N)<\bar{\delta}(N)$. The second inequality is shown to follow from $N \geq \sqrt{1+\Pi^{M} / c}$ in the proof of Theorem B.2. 
As for the inequality $\delta^{M}(N)>\underline{\delta}(N)$, write $\delta^{M}(N)$ as

$$
\delta^{M}(N)=\frac{1}{1+\frac{1}{N} \Pi^{M} / \widetilde{\Pi}^{M}}
$$

and $\underline{\delta}(N)$ as

$$
\underline{\delta}(N)=\frac{N}{N+1} \frac{1}{1+\frac{N}{N+1} \frac{\Pi^{M}-\widetilde{\Pi}^{M}}{c}} .
$$

Then re-arrangement of the inequality yields

$$
1+\frac{N}{N+1} \frac{\Pi^{M}-\widetilde{\Pi}^{M}}{c}>\frac{N}{N+1}\left(1+\frac{1}{N} \frac{\Pi^{M}}{\widetilde{\Pi}^{M}}\right) .
$$

Multiplying through by $N+1$ and cancelling terms leaves

$$
1+N \frac{\Pi^{M}-\widetilde{\Pi}^{M}}{c}>\frac{\Pi^{M}}{\widetilde{\Pi}^{M}} .
$$

Subtracting both sides by 1 and combining terms on the rhs allows us to cancel a common factor of $\Pi^{M}-\widetilde{\Pi}^{M}$. Finally, we are left with $\widetilde{\Pi}^{M}>c / N$, which is equivalent to the condition $\Pi^{M}>\Delta c D\left(p_{H}^{*}\right)+c / N$ in the theorem statement.

Proof of Theorem 13. This is a special case of Theorem B.4, with the inequality of property 6 weakened to provide a simpler expression.

Proof of Theorem 14. Writing $\delta^{M}(N)$ as

$$
\delta^{M}(N)=1-\frac{1}{1+N \widetilde{\Pi}^{M} / \Pi^{M}}
$$

proves that it is strictly increasing in $N$ and approaches 1 as $N \rightarrow \infty$. Similarly, writing $\underline{\delta}(N)$ as

$$
\underline{\delta}(N)=\left(1+\frac{1}{N}+\frac{\Pi^{M}-\widetilde{\Pi}^{M}}{c}\right)^{-1}
$$

shows that $\underline{\delta}(N)$ is strictly increasing but bounded below 1 .

To finish the proof, we must show that $\Delta(N) \equiv \delta^{M}(N)-\underline{\delta}(N)$ is increasing whenever $\Delta(N) \geq 0$. We showed in the proof of Theorem 12 that the latter inequality holds iff $\widetilde{\Pi}^{M} \geq c / N$. It is then sufficient to verify that $\Delta^{\prime}(N)>0$ whenever $N \geq c / \widetilde{\Pi}^{M}$. 
Computing the derivative of $\Delta(N)$ yields

$$
\Delta^{\prime}(N)=\frac{\widetilde{\Pi}^{M} / \Pi^{M}}{\left(1+N \frac{\widetilde{\Pi}^{M}}{\Pi^{M}}\right)^{2}}-\frac{1 / N^{2}}{\left(1+\frac{1}{N}+\frac{\Pi^{M}-\widetilde{\Pi}^{M}}{c}\right)^{2}} .
$$

Some re-arrangement shows that $\Delta^{\prime}(N)>0$ iff

$$
1+\frac{\Pi^{M}-\widetilde{\Pi}^{M}}{c}>\sqrt{\frac{\widetilde{\Pi}^{M}}{\Pi^{M}}}+\frac{1}{N}\left(\sqrt{\frac{\Pi^{M}}{\widetilde{\Pi}^{M}}}-1\right) .
$$

Because $\Pi^{M}>\widetilde{\Pi}^{M}$, the rhs is largest when $N$ is smallest, i.e. at $N=c / \widetilde{\Pi}^{M}$. It is therefore sufficient to show that

$$
1+\frac{\Pi^{M}}{c}>\sqrt{\frac{\widetilde{\Pi}^{M}}{\Pi^{M}}}+\frac{\sqrt{\Pi^{M} \widetilde{\Pi}^{M}}}{c} .
$$

But the first term on the lhs is strictly greater than the first term on the rhs, with a similar comparison holding for the second terms. So indeed $\Delta^{\prime}(N)>0$ whenever $N \geq c / \widetilde{\Pi}^{M}$, completing the proof.

Proof of Theorem 15. Fix $\left(c_{H}, c_{A}\right)$ such that (A1) through (A3) hold, $\widetilde{\Pi}^{M}>c / N$, and either $N=1$ or $N \geq \sqrt{1+\Pi^{M} / c}$. Consider a decreasing sequence $c_{A}^{n} \leq c_{A}$ such that $c_{A}^{n} \downarrow c_{H}$. Note that (A1) through (A3) continue to hold for all $\left(c_{H}, c_{A}^{n}\right)$, and $\Pi^{M}$ is fixed while $\widetilde{\Pi}^{M}$ is increasing with $n$. So $\widetilde{\Pi}^{M}>c / N$ and $N \geq \sqrt{1+\Pi^{M} / c}$ hold along the sequence as well.

Suppose first that $\delta<N /(N+1)$. Then $\delta^{M}(N)$ is increasing along the sequence, and for sufficiently large $n$ we have $\delta<\delta^{M}(N)$. Wlog we will assume this inequality holds along the entire sequence. Hence along the sequence the conditions of Theorem 9 hold along the sequence, and the sequence of optimal equilibrium profits $\Pi^{*, n}$ is characterized by

$$
\Pi^{*, n}=(1-\delta)\left(N \Pi^{*, n}-(N-1) \Delta c^{n} D\left(p^{*}\left(\Pi^{*, n}\right)\right)\right)+\delta \underline{\Pi}^{n}(\delta ; N) .
$$

(Note that $p^{*}(\cdot)$ is a function only of $c_{H}$ and so is unchanged along the sequence.)

Because $\Pi^{*, n} \in\left[0, \Pi^{M}\right]$ for all $n$ and $D\left(p^{*}(\cdot)\right)$ is continuous, the squeeze theorem implies that $\Delta c^{n} D\left(p^{*}\left(\Pi^{*, n}\right)\right) \rightarrow 0$ (regardless of whether the limit of the sequence $\Pi^{*, n}$ exists). Similarly, as $\underline{\Pi}^{n}(\delta ; N) \in\left[0, \Delta c^{n}\right]$, we have $\underline{\Pi}^{n}(\delta ; N) \rightarrow 0$. Thus $(1-N(1-\delta)) \Pi^{*, n} \rightarrow 0$, i.e. $\Pi^{*, n} \rightarrow 0$.

On the other hand, suppose $\delta \geq N /(N+1)$. Then $\delta \geq \delta^{M}(N)$ for all $n$, hence $\Pi^{*, n}=\Pi^{M}$ is a constant sequence with the stated limit. 
Proof of Theorem 16. Fix $c>0$ such that (A1) through (A3) hold, andconsider a decreasing sequence $c_{n} \leq c$ with limit 0 . Then (A1) through (A3) continue to hold along the sequence. Supposing that $\Pi^{*, n}$ tends to some definite limit independent of the sequence chosen, the claims in the theorem statement follow by inspecting the expressions derived in Theorem B.4. So we need only show that $\Pi^{*, n}$ converges, and to the same limit for all sequences.

Suppose first that

$$
\delta \geq \lim _{n \rightarrow \infty} \delta^{M}(N)=1-\frac{1}{1+N\left(p_{H}^{*}-c_{A}\right) /\left(p_{H}^{*}-c_{H}\right)}
$$

Then as $\delta^{M}(N)$ is strictly decreasing in $c$, for all $n$ we have $\delta>\delta^{M}(N)$ and thus $\Pi^{*, n}=\Pi^{M}$. The limit of this sequence is therefore $D\left(p_{H}^{*}\right)\left(p_{H}^{*}-c\right)$ regardless of the sequence chosen.

On the other hand, suppose $\delta$ lies below this threshold. Then for sufficiently large $n$ we have $\delta<\delta^{M}(N)$. Further, Theorem 11 implies that $\underline{\Pi}^{n}(\delta ; N)=0$ for sufficiently large $n$, given $\underline{\delta}(N) \rightarrow 0$. (Note that $\Pi^{M}-\widetilde{\Pi}^{M}=\Delta c D\left(p_{H}^{*}\right)$, which is independent of $n$.) Then $\Pi^{*, n}$ is characterized by

$$
\Pi^{*, n}=(1-\delta)\left((N+1) \Pi^{*, n}-\Delta c N D\left(p^{*, n}\left(\Pi^{*, n}\right)\right)\right)
$$

Observe that $p^{*, n}(\cdot)$ is decreasing pointwise in $n$, as a lower price is needed to obtain given profits for a smaller fixed cost. Then $\Pi^{*, n}$ is increasing in $n$, and as it is bounded above by $D\left(p_{H}^{*}\right)\left(p_{H}^{*}-c_{H}\right)$ its limit must exist, say $\Pi^{*, \infty}$. Continuity of $D(\cdot)$ then implies that $\Pi^{*, \infty}$ satisfies

$$
\Pi^{*, \infty}=(1-\delta)\left((N+1) \Pi^{*, \infty}-\Delta c N D\left(\lim _{n \rightarrow \infty} p^{*, n}\left(\Pi^{*, n}\right)\right)\right) .
$$

Now, $p^{*, n}(\cdot)$ converges uniformly ${ }^{25}$ to $p^{*, \infty}(\cdot)$, which is a continuous function defined via

$$
\Pi=D(p)\left(p-c_{H}\right)
$$

An easy argument ${ }^{26}$ then shows that $\lim _{n \rightarrow \infty} p^{*, n}\left(\Pi^{*, n}\right)=p^{*, \infty}\left(\Pi^{*, \infty}\right)$.

\footnotetext{
${ }^{25}$ There is a difficulty as to the domain over which convergence occurs, as higher profits are possible the lower is $c$. We take the domain to be $\left[0, D\left(p_{H}^{*}\right)\left(p_{H}^{*}-c\right)\right]$ for all $n$, and simply extend each $p^{*, n}(\cdot)$ continuously to the top of this domain by taking it to be a constant function.

${ }^{26}$ Take a sequence of functions $f_{n}$ converging uniformly to a continuous function $f$ on some domain $X$, and a sequence $x_{n}$ converging to $x$ in $X$. Then $\left|f_{n}\left(x_{n}\right)-f(x)\right| \leq\left|f_{n}\left(x_{n}\right)-f\left(x_{n}\right)\right|+\left|f\left(x_{n}\right)-f(x)\right|$ by the triangle inequality, and the first term on the rhs converges to zero given the uniform convergence of the $f_{n}$, while the second term vanishes by continuity of $f$.
} 
We conclude that $\Pi^{*, \infty}$ exists and is defined implicitly by

$$
\Pi^{*, \infty}=(1-\delta)\left((N+1) \Pi^{*, \infty}-\Delta c N D\left(p^{*, \infty}\left(\Pi^{*, \infty}\right)\right)\right)
$$

independent of the particular sequence chosen.

\section{E An equilibrium in non-market-symmetric strategies}

In this Appendix we demonstrate parameters under which collusion in market-symmetric strategies is Pareto-dominated by collusion in more general strategies. Fix $D(p)=\mathbf{1}\{p \leq v\}$, $N=2, \delta=0.6, \Delta c=0.2$, and $c=0.1$. $v$ will be assumed to be sufficiently large. The largest partially collusive profits which can be supported in this environment satisfy

$$
\Pi^{*}=(1-\delta)\left(N \Pi^{*}-(N-1) \Delta c\right)
$$

yielding $\Pi^{*}=0.8$.

Now, consider a stationary equilibrium with profits taking the signs indicated in Table 1. Markets 2 and 3 take the standard structure of Theorem B.4.

In market 1 , let $\underline{p} \equiv \Pi_{1}^{1}+c+c_{H}, \bar{p}_{1} \equiv \frac{1}{2}\left(v+c_{H}\right)$, and $\bar{p}_{2} \equiv \frac{1}{2}\left(v+c_{H}\right)$. Firm 3 does not enter. Firms 1 and 2 always enter and play

$$
F_{1}^{1}(p)= \begin{cases}0, & p<\underline{p}, \\ 1-\frac{\underline{p}-c_{A}}{p-c_{A}}, & p \in\left[\underline{p}, \bar{p}_{1}\right), \\ 1-\frac{\underline{p}-c_{A}}{\bar{p}_{2}-c_{A}}, & p \in\left[\bar{p}_{1}, v\right), \\ 1, & p \geq v\end{cases}
$$

and

$$
F_{1}^{2}(p)= \begin{cases}0, & p<\underline{p}, \\ 1-\frac{\underline{p}-c_{H}}{\bar{p}-c_{H}}, & p \in\left[\underline{p}, \bar{p}_{1}\right), \\ 1-\frac{\underline{p}-c_{H}}{\bar{p}_{1}-c_{H}}, & p \in\left[\bar{p}_{1}, v\right), \\ 1, & p \geq v .\end{cases}
$$

These two distributions are continuous with full support on $\left[v, \bar{p}_{1}\right)$ and then have a gap on 
$\left(\bar{p}_{1}, v\right)$. Firm 1 also places an atom at $\bar{p}_{1}$. Finally, both firms place an atom at $v$, of sizes

$$
\Delta F_{1}^{1}=2\left(\frac{\Pi_{1}^{2}+c}{\Pi^{M}+c-\Delta c}\right), \quad \Delta F_{1}^{2}=2\left(\frac{\Pi_{1}^{1}+c}{\Pi^{M}+c}\right) .
$$

The two firms' profits are related by $\Pi_{1}^{2}=\Pi_{1}^{1}-\Delta c$. In order for this construction to be welldefined, we need $\underline{p}<\bar{p}_{1}$, or equivalently $\Pi_{1}^{1}<\frac{1}{2}\left(\Pi^{M}-c\right)$, which is satisfied for $v$ sufficiently large.

The best deviation by each of firms 1 and 2 in market 1 is to undercut the atom at $p=v$, which yields them profits $2 \Pi_{1}^{i}+c$. Meanwhile firm 3 has two possible maximally profitable deviations, one at $p=\underline{p}$ and another by undercutting $p=v$. (It can't be more profitable to price in the firms' price support, as this will make firm 3 strictly less than firm 2 would by playing there, and thus strictly less than he would make by playing $p=\underline{p}$.) His profits at $\underline{p}$ are $\Pi_{1}^{2}$, while his profits undercutting $v$ are

$$
\left(\Pi^{M}+c-\Delta c\right) \Delta F_{1}^{1} \Delta F_{1}^{2}-c=4\left(\Pi_{1}^{2}+c\right) \frac{\Pi_{1}^{1}+c}{\Pi^{M}+c}-c .
$$

For sufficiently large $v$, these are lower than his profits at $\underline{p}$.

Thus, for sufficiently large $v$ the incentive constraints which need to be satisfied are

$$
\Pi_{1}^{1} \geq(1-\delta)\left(2 \Pi_{1}^{1}+c+\Pi_{2}^{2}+\Pi_{3}^{3}-2 \Delta c\right)
$$

for firm 1 ,

$$
\Pi_{1}^{2}+\Pi_{1}^{2} \geq(1-\delta)\left(2 \Pi_{1}^{2}+c+\Pi_{2}^{2}+\Pi_{3}^{3}-\Delta c\right)
$$

for firm 2 , and

$$
\Pi_{3}^{3} \geq(1-\delta)\left(\Pi_{1}^{2}+\Pi_{2}^{2}+\Pi_{3}^{3}-\Delta c\right)
$$

for firm 3. In addition, $\Pi_{1}^{2}=\Pi_{1}^{1}-\Delta c$. It is easily checked that all firms' profits are simultaneously maximized subject to the IC constraints when $\Pi_{1}^{1}=1.4, \Pi_{1}^{2}=1.2, \Pi_{2}^{2}=0.2$, and $\Pi_{3}^{3}=0.8$. This equilibrium is actually a Pareto-improvement on the best partially collusive one!

\section{F An equilibrium with no home market profits}

In this Appendix we demonstrate parameters under which collusion in which profits are won in each firm's home market is Pareto-dominated by collusion in which profits are won only 
in firms' away markets. Fix $D(p)=\mathbf{1}\{p \leq v\}, N=2, \delta=0.62, \Delta c=0.2$, and $c=0.1$. $v$ will be assumed to be sufficiently large. The maximal profits supportable by an equilibrium of the type characterized in Theorem B.4 (which is the best that can be done when firms earn profits only in their home market) satisfy

$$
\Pi^{*}=(1-\delta)\left(N \Pi^{*}-(N-1) \Delta c\right)
$$

or $\Pi^{*} \simeq 1.09$.

Now consider a market-symmetric equilibrium in which all away firms make positive profits $\Pi / N$ in each market, while the home firm makes no profits. Thus each firm makes total equilibrium profits $\Pi$.

The home firm refrains from entering, while the away firms always enter. Let $p \equiv$ $\Pi / N+c+c_{A}$ and $\bar{p} \equiv c_{A}+\frac{1}{N}\left(v-c_{A}\right)$. Each away firm plays

$$
F^{A}(p)= \begin{cases}0, & p<\Pi+c+c_{A}, \\ 1-\left(\frac{\underline{p}-c_{A}}{\bar{p}-c_{A}}\right)^{1 /(N-1)}, & p \in[\underline{p}, \bar{p}), \\ 1-\left(\frac{\underline{p}-c_{A}}{\bar{p}-c_{A}}\right)^{1 /(N-1)}, & p \in[\bar{p}, v), \\ 1, & p \geq v .\end{cases}
$$

Each firm's price distribution is continuous with full support on $[\underline{p}, \bar{p}]$, has a gap on $[\bar{p}, v)$, and places an atom at $\bar{p}$ of strength

$$
\Delta F^{A}=\left[N\left(\frac{\underline{p}-c_{A}}{v-c_{A}}\right)\right]^{1 /(N-1)} .
$$

For the equilibrium to be well-defined, we need $\bar{p}>p$, i.e. $\Pi<v-c_{A}-N c$, which is possible for $v$ sufficiently large.

Now, each away firm has a deviation to undercutting $p=v$, yielding profits $\Pi+(N-1) c$. Meanwhile the home firm has two candidate deviations. Setting $p=\underline{p}$ yields profits $\Pi / N+$ $\Delta c$, while undercutting $p=v$ yields profits

$$
\left(v-c_{H}\right)\left(\Delta F^{A}\right)^{N}-c=N^{N /(N-1)} \frac{v-c_{H}}{\left(v-c_{A}\right)^{N /(N-1)}}-c .
$$

For $v$ sufficiently large the home firm's most profitable deviation is to $\underline{p}$. 
The IC constraint required to support this equilibrium is then

$$
\Pi \geq(1-\delta)\left[\left(N+\frac{1}{N}\right) \Pi+N(N-1) c+\Delta c\right],
$$

with the additional constraint that $\Pi<v-c_{A}-N c$. Given that $(1-\delta)(N+1 / N)=0.95<1$, any $\Pi \geq 3.04$ will satisfy the $\mathrm{IC}$ constraint. So for $v$ sufficiently high, there exist $\Pi>\Pi^{*}$ supportable in equilibrium. 